\title{
3 Researc Sguare

\section{Energy Management Optimization Based on Aging Adaptive Functional State Model of Battery For Intelligent Vehicles Driven by Internal Combustion Engine}

Weiwei Kong ( $\square$ kongwei_1987@hotmail.com )

China Agricultural University https://orcid.org/0000-0003-2144-4236

Yugong Luo

Tsinghua University

Xiaomin Lian

Tsinghua University

Fachao Jiang

China Agricultural University

\section{Original Article}

Keywords: Aging adaptive functional state model, Energy management optimization, Battery protection, Internal combustion engine vehicles

Posted Date: May 27th, 2021

DOI: https://doi.org/10.21203/rs.3.rs-541031/v1

License: (9) This work is licensed under a Creative Commons Attribution 4.0 International License.

Read Full License 


\title{
Energy Management Optimization Based on Aging Adaptive Functional State Model of Battery For Intelligent Vehicles Driven by Internal Combustion Engine
}

\author{
Weiwei Kong ${ }^{* 1}$, Yugong Luo $^{2}$, Xiaomin Lian $^{2}$, and Fachao Jiang ${ }^{1}$ \\ 1. College of Engineering, China Agricultural University, Beijing 100083, Chinas \\ 2. School of Vehicle and Mobility, Tsinghua University, Beijing 100084, China \\ Corresponding author: Weiwei Kong, E-mail: kongwei_1987@hotmail.com
}

\begin{abstract}
With the development of intelligent vehicles, increasing number of electronic and electrical devices are applied in vehicles, the necessary power is surging, battery protection is increasingly required, and higher demands are made for energy management. Most previous studies on battery characteristics have only focused on the battery itself, which is chemical characteristics. Further considering battery's actual operating conditions on vehicles, battery's functional characteristics are proposed and studied in this paper. Aging adaptive functional state model of battery for internal combustion engine vehicles is proposed, comprehensively revealing the operating characteristics covering the battery full life cycle. Thereafter, based on the model, a battery protection scheme is developed, including overdischarge and graded over-current protection to achieve comprehensive battery protection. Furthermore, a model-based energy management strategy is presented to achieve integrated optimization of fuel economy, battery protection, and vehicle power performance. Finally, tests are performed on the vehicle and test bench to verify the validity and feasibility of the proposed model and management scheme. Results reveal that the model can reflect battery's functional features, over-current protection and over-discharge protection of the battery are achieved, and the vehicle start-up capability is secured. The proposed energy management strategy can effectively improve fuel economy.
\end{abstract}

KEY WORDS : Aging adaptive functional state model, Energy management optimization, Battery protection, Internal combustion engine vehicles

\section{NOMENCLATURE}

$Q_{\mathrm{N}}$ : nominal capacity, Ah

$Q_{\mathrm{D}}$ : dead power, Ah

$Q_{\mathrm{R}}$ : actual capacity, Ah

$Q_{\mathrm{B}}$ : discharged electric power, $\mathrm{Ah}$

$Q_{\mathrm{S}}$ : remaining electric power, Ah

$S_{\mathrm{X}}$ : unknown state

$S_{\mathrm{F}}$ : fully charged state

$S_{\mathrm{L}}, \hat{S}_{\mathrm{L}}$ : start-up zone

$S_{\mathrm{P}}, \hat{S}_{\mathrm{P}}$ : protection zone

$S_{\mathrm{C}}, \hat{S}_{\mathrm{C}}$ : transition zone

$S_{\mathrm{R}}, \hat{S}_{\mathrm{R}}$ : recycling zone

$l_{1}, l_{2}, p_{1}, p_{2}, p_{3}, c_{1}, c_{2}, c_{3}$ : feature points of function zones

$\mathrm{Q}_{1}, \mathrm{Q}_{2}, \mathrm{Q}_{3}$ : boundaries of aging zones, $\mathrm{Ah}$

$A_{\mathrm{X}}$ : unknown aging state

$A_{\mathrm{F}}$ : abandoned zone

$A_{\mathrm{R}}$ : replaced zone

$A_{\mathrm{U}}$ : usable zone

$A_{\mathrm{H}}$ : healthy zone

$k_{\mathrm{T}}$ : temperature correction coefficient

$I_{\mathrm{M}}$ : measured current, $\mathrm{A}$

$I_{\mathrm{R}}$ : rated current, $\mathrm{A}$

\author{
$k$ : overload ratio \\ $t$ : delayed cutoff time, $\mathrm{s}$ \\ $U_{\mathrm{N}}$ : normal charge voltage, $\mathrm{V}$ \\ $U_{\mathrm{H}}$ : quick charge voltage, $\mathrm{V}$ \\ $U_{\mathrm{R}}$ : charge voltage of recovery mode, $\mathrm{V}$ \\ $U_{\mathrm{F}}$ : floating charge voltage, $\mathrm{V}$
}

\section{INTRODUCTION}

Studies on the battery characteristics and battery management strategy are crucial to protect the battery from the damage, prolong its lifetime, and improve the fuel economy of vehicles, especially for intelligent vehicles (IVs), which require more electric power. Whereas, most previous studies on battery characteristics have focused on the battery itself without considering its actual operating conditions, which is chemical characteristics of the battery. Previous studies on vehicle energy management have probably focused on electric vehicles (EVs). Whereas for the intelligent vehicles driven by internal combustion engine (ICE), battery management system still follows the old pattern from decades ago, which is rather simple and rough. With the increasing number of electronic and electrical devices (EEDs) [1-2] and functional modules such as advanced driver assistance system (ADAS) [3] applied in IVs, the required power is surging and the demands for battery management are increasing. This research is carried out 
to solve these two problems. Battery's functional characteristics combining its actual operating conditions with its chemical characteristics is proposed and analyzed in this paper; then based on the proposed functional state model, a battery protection scheme is developed, including over-discharge and graded overcurrent protection; thereafter, model-based energy management optimization strategy is presented to achieve the integrated optimization of fuel economy, battery protection, and vehicle power performance.

With the development of EVs, battery management systems (BMSs) have gained extensive attention. Researchers have made significant efforts in the study of BMS, and fruitful results have been achieved [4-10]. BMS usually contains the following functions: state monitoring, such as state of charge (SOC) and state of health $(\mathrm{SOH})$ estimation, cell balancing, and thermal management [11-13]. State monitoring involves estimating the SOC and $\mathrm{SOH}$ according to the measured battery parameters, and state monitoring forms the foundation of battery management and control. Common estimation methods include discharging counting, Ampere-hour counting (Coulomb counting), open circuit voltage [14-16], the neural network method [17-19], the fuzzy logic method [20], support vector machine (SVM) [21], and the Kalman filter approach [22-24]. In terms of cell balancing and thermal management, numerous research results have been achieved [25-28]. Imtiaz [29] and Wang et al. [30] both selected the work voltage as the basis for balancing judgment. Daowd et al. [31] drew the conclusion that the battery pack could achieve improved consistency with SOC if the SOC estimation accuracy could reach a certain level. For thermal management, Forgez et al. [32] proposed a thermal model of a cylindrical $\mathrm{LiFePO}_{4} /$ graphite lithium-ion battery with lumped parameters to estimate the temperature response. Guo et al. [33] developed a 3D thermal model for analyzing the temperature distribution under abuse conditions. As can be observed from the researches above, BMS functions are mainly used for power batteries in EVs, not applicable to the battery management of IVs driven by ICE.

Few studies are carried out regarding battery management for ICE vehicles. Only certain high-end cars with many EEDs are equipped with battery management systems. Their functions are rather simple, mainly consisting of battery state monitoring and charge/discharge current control by controlling the generator. For example, in Park Avenue of GM, the body control module (BCM) estimated SOC using the battery voltage, current, and temperature, and sent the desired charge current value to the engine control module (ECM). ECM controlled the generator to reach the desired charge current [34]. VARTA Automotive [35] proposed a battery monitoring and energy management system. One battery state detection module was responsible for the
SOC and SOH estimation, while the generator management and consumer management modules were responsible for the battery charge/discharge control. The LS430, produced by the Toyota Motor Corporation [34], limited the charge current when the temperature of the battery electrolyte was very high, in order to prolong the battery lifetime.

As described above, for ICE vehicles, only certain high-end vehicles are equipped with battery management systems, with rather simple functions such as battery state monitoring and charge current control. Therefore, the battery for ICE vehicles suffers from a lack of comprehensive management and sufficient protection. More importantly, although battery characteristics or battery full life cycle model is revealed in the process of state estimation study, studies are more concerned about chemical properties of battery itself, not considering its actual operating conditions. This paper proposes functional characteristics of battery in practical applications, and studies functional characteristics covering the battery full life cycle. In addition, a comprehensive protection and optimization management scheme for the battery of IVs driven by ICE are established in this paper. The main contributions are as follows

1) A functional state model (FSM) of battery for IVs driven by ICE is proposed to analyze functional characteristics. According to the operating conditions of battery for IVs driven by ICE and battery state of charge, a battery is divided into various functional zones which reflect different practical characteristics. Furthermore, compared with chemical characteristics, this model is more closely related to the practical conditions of the battery, and therefore this model can be applied to various types of batteries of IVs driven by ICE.

2) An aging adaptive functional state model (AAFSM) of battery is established, with function zones dynamically adjusting with different battery aging states. Battery aging zones are presented to describe different aging stages of battery from the perspective of practical applications. The incidence relationship between functional characteristics and battery aging effects is further elaborated. Therefore, AAFSM reveals functional characteristics covering the battery full life cycle. Similarly, AAFSM of battery is applicable to various types of batteries of IVs driven by ICE by adjusting values of feature points.

3) Based on AAFSM, comprehensive battery management methods for IVs driven by ICE are developed, including a battery protection scheme and an energy optimization management strategy. With overdischarge protection and graded over-current protection, the battery can be protected effectively and comprehensively, start-up capability is secured, and electric power supply safety can be achieved. With the energy management strategy, fuel economy can be 
improved considering battery protection and vehicle power performance.

The remainder of this paper is organized as follows. Section 2 introduces the FSM of battery for IVs driven by ICE. Section 3 elaborates on AAFSM of battery for IVs driven by ICE. Section 4 presents a model-based protection scheme of the battery, and the energy management strategy is introduced in section 5. Section 6 describes the experiments performed on the vehicle and test bench. Section 7 presents the main conclusions of this investigation.

\section{FUNCTIONAL STATE MODEL OF BATTERY FOR IVS DRIVEN BY ICE}

Battery characteristics are an important basis for battery management, and their study face two challenges. The characteristics need to be studied extendedly, taking battery's actual operating conditions into account; moreover, battery characteristics change as the battery ages. Considering the practical conditions, FSM of battery without the influence of battery aging is proposed to study its functional characteristics. Then AAFSM of battery is further established, which will be described in section 3.

From the perspective of actual usage, a battery can be represented by several state variables, as illustrated in Fig. 1. $Q_{\mathrm{N}}$ refers to the nominal capacity, which is an invariant, and $Q_{\mathrm{D}}$ refers to the dead power, which cannot be used owing to the battery aging. As the battery ages, $Q_{\mathrm{D}}$ gradually increases. Thus, $Q_{\mathrm{R}}$ is the actual capacity that can be withdrawn from the battery, which is a slowly decreasing state variable. Moreover, $Q_{\mathrm{B}}$ represents the discharged electric power, and $Q_{\mathrm{S}}$ is the remaining electric power, which are both dynamic variables.

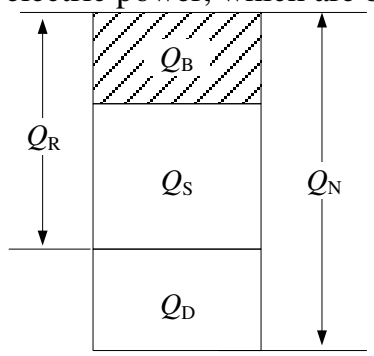

Figure 1. State variables of battery.

In practical applications, $Q_{\mathrm{D}}$ is worthless, and therefore FSM of battery is studied for $Q_{\mathrm{R}}$. According to the actual usage conditions, the battery can be divided into several function zones, namely the recycling, transition, protection, and start-up zones, as illustrated in Fig. 2, where $Q_{\mathrm{C}}, Q_{\mathrm{P}}$, and $Q_{\mathrm{L}}$ are the thresholds of these four zones. Combined with two special states, the functional state of the battery, $s_{\mathrm{C}}$, can be expressed as Eq. (1).

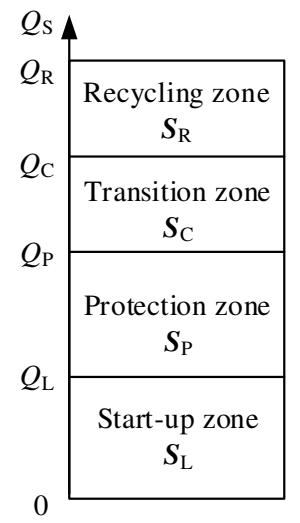

Figure 2. Function zones of battery.

$$
s_{\mathrm{C}}= \begin{cases}\boldsymbol{S}_{\mathrm{X}} & Q_{\mathrm{S}} \text { is unknown } \\ \boldsymbol{S}_{\mathrm{L}} & 0 \leq Q_{\mathrm{S}} \leq Q_{\mathrm{L}} \\ \boldsymbol{S}_{\mathrm{P}} & Q_{\mathrm{L}}<Q_{\mathrm{S}} \leq Q_{\mathrm{P}} \\ \boldsymbol{S}_{\mathrm{C}} & Q_{\mathrm{P}}<Q_{\mathrm{S}} \leq Q_{\mathrm{C}} \\ \boldsymbol{S}_{\mathrm{R}} & Q_{\mathrm{C}}<Q_{\mathrm{S}}<Q_{\mathrm{R}} \\ \boldsymbol{S}_{\mathrm{F}} & Q_{\mathrm{S}}=Q_{\mathrm{R}}\end{cases}
$$

Prior to achieving the battery state estimation, the remaining electric power $Q_{\mathrm{S}}$ is unknown, and the battery is in an unknown state, $\boldsymbol{S}_{\mathrm{X}}$. When the battery is fully charged, namely $Q_{\mathrm{S}}=Q_{\mathrm{R}}$, the battery is in a fully charged state, $\boldsymbol{S}_{\mathrm{F}}$.

Start-up zone $S_{\mathrm{L}}$ is used to supply the electric power for the vehicle to start up, while $Q_{\mathrm{L}}$ is the electric power required for the engine launch. If the battery is in the start-up zone, it has already been seriously overdischarged, and the vehicle is probably unable to start up; thus, the battery must be charged immediately.

When the engine shuts down, certain EEDs, such as the headlights, are still able to work. The electric power of the protection zone serves these EEDs and the vehicle quiescent consumption. If the battery is in this zone, the driver should be alerted that the battery has been slightly over-discharged. Then, the battery needs to be protected: no further discharge and charging the battery in a timely manner in order to ensure that the vehicle can start after being parked for a lengthy period.

Recycling zone $S_{\mathrm{R}}$ is a safe zone, which is to say there is no need to worry about the start-up capability. Therefore, if the battery is in this zone, it can bear discharging for a while, and the recycling zone is reserved for storing the recovered energy. The battery is no longer charged until $Q_{\mathrm{S}}<Q_{\mathrm{C}}$, except when the vehicle is braking.

Transition zone $S_{\mathrm{C}}$ is the transition buffer between the recycling and protection zones, to protect the battery from frequent switching between charging and discharging. The frequent switching not only damages the battery but also has a serious impact on the engine 
owing to the frequent generator switches. In practical applications, the battery is usually in the transition zone.

\section{AGING ADAPTIVE FUNCTIONAL STATE MODEL OF BATTERY FOR IVS DRIVEN BY ICE}

The function zone partitioning represented in Fig. 2 does not consider the battery aging effect. As the battery ages, its function zones will change. For example, for a new battery, its actual capacity $Q_{\mathrm{R}}$ is sufficient enough to possess a large recycling zone, while for an aged battery with a smaller capacity, the recycling zone is compressed. If $Q_{\mathrm{R}}$ is excessively small, the recycling zone even disappears to ensure that the vehicle works properly. Taking battery aging effects into account, the AAFSM of battery is established, in which function zones dynamically adjust as battery ages. Based on AAFSM, battery aging zones are formulated, and the incidence relationship between battery functional states and aging states is revealed.

\subsection{Aging adaptive function zones of battery}

Battery functional state and aging state constitute the battery full life cycle state space, which can be represented by a triangle, as illustrated in Fig. 3. The horizontal axis is the actual capacity $Q_{\mathrm{R}}$, representing the battery aging state. In the life cycle, the actual capacity is an independent variable, with a range of 0 to $Q_{\mathrm{N}}$, and it is expressed by $q_{\mathrm{R}}$ in order to be distinguished. The vertical axis represents the remaining electric power expressed by $q_{\mathrm{S}}$ as an independent variable with a range of 0 to $Q_{\mathrm{N}}$. The isosceles right triangle represents the battery state space covering full life cycle, as indicated in Fig. 3.

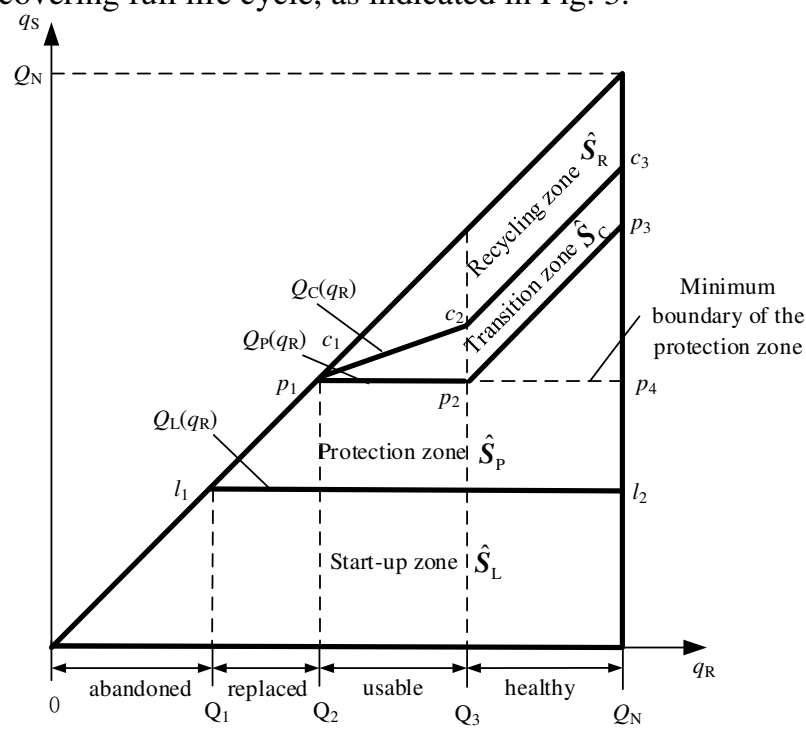

Figure 3. Battery full life cycle state space.

The battery dynamic functional state $\hat{s}_{\mathrm{C}}$ can be expressed as follows:
$\hat{S}_{\mathrm{C}} \in\left\{\boldsymbol{S}_{\mathrm{X}}, \hat{\boldsymbol{S}}_{\mathrm{L}}, \hat{\boldsymbol{S}}_{\mathrm{P}}, \hat{\boldsymbol{S}}_{\mathrm{C}}, \hat{\boldsymbol{S}}_{\mathrm{R}}, \boldsymbol{S}_{\mathrm{F}}\right\}$.

As illustrated in Fig. 3, the recycling, transition, protection, and start-up zones change as the battery ages, and these are expressed as $\hat{\boldsymbol{S}}_{\mathrm{R}}, \hat{\boldsymbol{S}}_{\mathrm{C}}, \hat{\boldsymbol{S}}_{\mathrm{P}}$, and $\hat{\boldsymbol{S}}_{\mathrm{L}}$, respectively. Different from basic function zones illustrated in Fig. 2, the function zone boundaries are equations of $q_{\mathrm{R}}$, expressed as $Q_{\mathrm{L}}\left(q_{\mathrm{R}}\right), Q_{\mathrm{P}}\left(q_{\mathrm{R}}\right)$, and $Q_{\mathrm{C}}\left(q_{\mathrm{R}}\right)$, respectively. Function zones can be expressed by the following equations.

$$
\begin{aligned}
& \hat{\boldsymbol{S}}_{\mathrm{R}}=\left\{\left(q_{\mathrm{R}}, q_{\mathrm{S}}\right) \mid Q_{\mathrm{C}}\left(q_{\mathrm{R}}\right)<q_{\mathrm{S}} \leq q_{\mathrm{R}}, \mathrm{Q}_{2} \leq q_{\mathrm{R}} \leq Q_{\mathrm{N}}\right\} \\
& \hat{\boldsymbol{S}}_{\mathrm{C}}=\left\{\left(q_{\mathrm{R}}, q_{\mathrm{S}}\right) \mid Q_{\mathrm{P}}\left(q_{\mathrm{R}}\right)<q_{\mathrm{S}} \leq Q_{\mathrm{C}}\left(q_{\mathrm{R}}\right), \mathrm{Q}_{2} \leq q_{\mathrm{R}} \leq Q_{\mathrm{N}}\right\} \\
& \hat{\boldsymbol{S}}_{\mathrm{P}}=\left\{\left(q_{\mathrm{R}}, q_{\mathrm{S}}\right) \mid Q_{\mathrm{L}}\left(q_{\mathrm{R}}\right)<q_{\mathrm{S}} \leq Q_{\mathrm{P}}\left(q_{\mathrm{R}}\right), \mathrm{Q}_{2} \leq q_{\mathrm{R}} \leq Q_{\mathrm{N}}\right\} \\
& \qquad\left\{\left(q_{\mathrm{R}}, q_{\mathrm{S}}\right) \mid Q_{\mathrm{L}}\left(q_{\mathrm{R}}\right)<q_{\mathrm{S}} \leq q_{\mathrm{R}}, \mathrm{Q}_{1} \leq q_{\mathrm{R}} \leq \mathrm{Q}_{2}\right\}
\end{aligned}
$$

In Eq. (7), (8), and (9), $q_{\mathrm{R}}$ is the independent variable, and $f$ represents the linear expression determined by two feature points, given as

$$
f(p, q, x)=\frac{y_{1}-y_{0}}{x_{1}-x_{0}} x+\frac{x_{1} y_{0}-x_{0} y_{1}}{x_{1}-x_{0}},
$$

where $p\left(x_{0}, y_{0}\right)$ and $q\left(x_{1}, y_{1}\right)$ are feature points which determine the line.

Combining Fig. 3 and the above Eqs., the physical descriptions and specific analysis of aging adaptive function zones are as follows.

1) Boundary line of the start-up zone depends on the electric power that vehicle requires to start up, and it can be obtained by experiments. The start-up electricity power varies slightly for the same vehicle as the temperature changes, although it is generally stable. In this study, no matter what temperature is, the boundary $Q_{\mathrm{L}}\left(q_{\mathrm{R}}\right)$ is set as a constant value for one vehicle for simplification, represented by the line $l_{1}-l_{2}$. Then $\mathrm{Q}_{1}$ is generated by the intersection of line $l_{1}-l_{2}$ and the hypotenuse. The value of $\mathrm{Q}_{1}$ can be obtained, too.

2) For a vehicle, its quiescent current is determined at the design stage. Therefore the minimum boundary of the protection zone is determined, which is the line $p_{1}-p_{4}$. If the battery is sufficiently healthy $\left(q_{\mathrm{R}}>\mathrm{Q}_{3}\right)$, the available capacity is redundant for the recycling and transition zones, and then the protection zone boundary can be 
raised properly in order to increase the reserved power for static consumption. Therefore, the final boundary of the protection zone is the polyline $p_{1}-p_{2}-p_{3}$, as illustrated in Fig. 3. Produced by feature point $p_{2}, \mathrm{Q}_{3}$ is the threshold of the battery healthy zone.

3) When the battery is healthy $\left(q_{R}>Q_{3}\right)$, recycling and transition zones can possess fixed capacities, represented by lines $c_{2}-c_{3}$ and $p_{2}-p_{3}$. Then, it is easy to determine that lines $c_{2}-c_{3}$ and $p_{2}-p_{3}$ are parallel to the hypotenuse of the triangle. When the battery is not sufficiently healthy $\left(q_{\mathrm{R}}\right.$ $<\mathrm{Q}_{3}$ ), the remaining capacity after removing the indispensable start-up and protection zones is not sufficient. The remaining capacity is allocated to the recycling and transition zones according to a certain proportion, and the boundary line is $c_{1}-c_{2}$. Feature points $c_{2}, c_{3}, p_{2}, p_{3}$ can be obtained, after determining recycling capacity as individual designs. $c_{1}$ and $p_{1}$ are one point. Moreover, $\mathrm{Q}_{2}$ is produced by feature point $c_{1}$, which is the energy recovery threshold. It is to say that if the battery of a vehicle ages to the extent of $q_{\mathrm{R}} \leq \mathrm{Q}_{2}$, the vehicle cannot perform energy recovery. Otherwise, it is likely that the vehicle cannot startup successfully.

From the above, it can be seen that all parameters in Figure 3 can be quantitatively determined. Some are determined according to the characteristics of the vehicle itself, such as $l_{1}-l_{2}, p_{1}-p_{4}$. In this study, these parameters are designed in advance and further calibrated through the vehicle experiments. Some are optimally designed according to different performance requirements, such as $c_{2}-c_{3}$ and $p_{2}-p_{3} . c_{2}-c_{3}$ is determined by the size of recycling zone, which directly affects the energy recovery performance of the vehicle. $p_{2}-p_{3}$ is determined by the size of transition zone, which affects the battery's switching frequency between charging and discharging. And other parameters such as $\mathrm{Q}_{1}, \mathrm{Q}_{2}, \mathrm{Q}_{3}$ can be calculated based on $l_{1}-l_{2}, p_{1}-p_{4}$ and $c_{2}-c_{3}$.

\subsection{Aging zones of battery}

As indicated in Fig. 3, a battery is divided into four aging zones, namely the healthy, usable, replaced, and abandoned zones. The boundaries are $\mathrm{Q}_{1}, \mathrm{Q}_{2}$, and $\mathrm{Q}_{3}$, respectively. The battery aging state $s_{\mathrm{h}}$ is expressed as Eq. (11), and the definitions are presented in Table 1.

$$
s_{\mathrm{h}}= \begin{cases}\boldsymbol{A}_{\mathrm{X}} & Q_{\mathrm{R}} \text { is unknown } \\ \boldsymbol{A}_{\mathrm{F}} & 0 \leq Q_{\mathrm{R}} \leq \mathrm{Q}_{1} \\ \boldsymbol{A}_{\mathrm{R}} & \mathrm{Q}_{1}<Q_{\mathrm{R}} \leq \mathrm{Q}_{2} \\ \boldsymbol{A}_{\mathrm{U}} & \mathrm{Q}_{2}<Q_{\mathrm{R}} \leq \mathrm{Q}_{3} \\ \boldsymbol{A}_{\mathrm{H}} & \mathrm{Q}_{3}<Q_{\mathrm{R}} \leq Q_{\mathrm{N}}\end{cases}
$$

Table 1. Definitions of aging state $s_{\mathrm{h}}$.

\begin{tabular}{ccc}
\hline No. & Symbols of aging zones & Definitions \\
\hline 1 & $A_{\mathrm{X}}$ & Unknown aging state \\
\hline 2 & $\boldsymbol{A}_{\mathrm{F}}$ & Abandoned zone \\
\hline 3 & $\boldsymbol{A}_{\mathrm{R}}$ & Replaced zone \\
\hline
\end{tabular}

\begin{tabular}{ccc}
\hline 4 & $\boldsymbol{A}_{\mathrm{U}}$ & Usable zone \\
\hline 5 & $\boldsymbol{A}_{\mathrm{H}}$ & Healthy zone \\
\hline
\end{tabular}

Prior to achieving the battery state estimation, the actual capacity $Q_{\mathrm{R}}$ is unknown, and battery aging state is unknown. As its name implies, abandoned zone $\boldsymbol{A}_{\mathrm{F}}$ indicates that the battery is out of use and has to be abandoned. If the battery is in this zone, it is so aged that vehicle is probably unable to start up even if the battery is fully charged.

When a battery is in replaced zone $\boldsymbol{A}_{\mathrm{R}}$, energy recovery is no longer supported, the minimum static consumption cannot be satisfied, and the start-up capability is threatened. If the battery is in this zone, it should be replaced in a timely manner.

When a battery is in healthy zone $\boldsymbol{A}_{\mathrm{H}}$, it indicates that the actual capacity $Q_{\mathrm{R}}$ is sufficient, and recycling zone can possess more capacity. Therefore, the vehicle can exhibit superior energy recovery performance.

The usable zone $\boldsymbol{A}_{\mathrm{U}}$ is a transition between $\boldsymbol{A}_{\mathrm{H}}$ and $\boldsymbol{A}_{\mathrm{R}}$. In this zone, the vehicle can still recover energy, whereas the energy recovery performance degrades.

The aging zone partitioning clearly describes different aging stages of battery, from the perspective of practical applications.

According to the description of section 3, several points can be concluded about the proposed AAFSM of battery.

1) Relationship between battery functional state and aging state is revealed by Fig. 3. In short, as the battery ages, available function zones gradually decrease.

2) Quantitative relationships of Fig. 3 are expressed by the Eqs. (2) - (11). Boundaries of regions are determined by the feature points, and their values can be determined by experiments, design requirements, etc.

3) The proposed AAFSM of battery is more closely related to the practical conditions of the battery than its chemical characteristics. Therefore, this model is applicable to various types of batteries of ICE vehicles by adjusting values of feature points, according to different types of vehicles, batteries, and design requirements.

\section{MODEL-BASED PROTECTION SCHEME OF BATTERY}

A battery protection scheme is established based on the proposed AAFSM to prolong the lifetime, prevent damage to the battery, ensure start-up capability, and secure the electric power supply safety.

\subsection{Categories of battery protection strategy}

In general, there are three categories of the battery protection strategy: charging the battery by generator controlling, limiting the use of EEDs to reduce the discharge current, and sending warning messages to the 
driver, for which detailed descriptions are provided in Table 2.

Table 2. Descriptions of battery protection strategy.

\begin{tabular}{|c|c|c|}
\hline Category & Symbols & Descriptions \\
\hline \multirow{2}{*}{$\begin{array}{l}\text { Charge } \\
\text { control }\end{array}$} & $\mathbf{C}\left(U_{\mathrm{N}}\right)$ & Charge battery with normal voltage $U_{\mathrm{N}}$ \\
\hline & $\mathbf{C}\left(U_{\mathrm{H}}\right)$ & Charge battery with high voltage $U_{\mathrm{H}}$ \\
\hline \multirow{5}{*}{$\begin{array}{c}\text { Limit } \\
\text { discharging }\end{array}$} & $\mathbf{D}(1)$ & $\begin{array}{l}\text { Limitation grade 1: restriction for certain } \\
\text { entertainment EEDs, such as seat massage }\end{array}$ \\
\hline & $\mathbf{D}(2)$ & $\begin{array}{l}\text { Limitation grade 2: restriction for all } \\
\text { entertainment EEDs }\end{array}$ \\
\hline & $\mathbf{D}(3)$ & $\begin{array}{c}\text { Based on grade 2, restriction for infotainment } \\
\text { additionally }\end{array}$ \\
\hline & $\mathbf{D}(4)$ & $\begin{array}{c}\text { Based on grade } 3 \text {, restriction for auxiliary } \\
\text { EEDs additionally }\end{array}$ \\
\hline & $\mathbf{D}(5)$ & $\begin{array}{l}\text { Restriction for all EEDs except those needed } \\
\text { for vehicle starting and safe driving }\end{array}$ \\
\hline \multirow{4}{*}{$\begin{array}{l}\text { Message } \\
\text { warning }\end{array}$} & $\mathbf{M}(1)$ & $\begin{array}{c}\text { "Battery cannot be charged, please check } \\
\text { immediately" }\end{array}$ \\
\hline & $\mathbf{M}(2)$ & "Low battery, please recharge immediately" \\
\hline & $\mathbf{M}(3)$ & $\begin{array}{c}\text { "The battery is aged, please check and } \\
\text { replace it in time" }\end{array}$ \\
\hline & M (4) & $\begin{array}{c}\text { "The battery is seriously aged, please replace } \\
\text { it immediately" }\end{array}$ \\
\hline
\end{tabular}

As indicated in Table 2, charge control is carried out by controlling the battery charging voltage. If the voltage is too low, it takes a long time to charge the battery; if the voltage is too high, excessive charging current may cause the battery to heat up, which will affect the charging efficiency and damage the battery. Thus, the charging voltage should be adjusted appropriately under different conditions, such as battery temperatures and functional states. These are described further in Table 4 and Table 6.

For the battery aging state, the management mainly depends on sending necessary messages to the driver in order to ensure that the battery is dealt with in a timely manner, as indicated in Table 3 .

Table 3. Battery management for each aging state.

\begin{tabular}{cc}
\hline Aging state $s_{\mathrm{h}}$ & Message warning \\
\hline Unknown aging state $\boldsymbol{A}_{\mathrm{X}}$ & - \\
Healthy zone $\boldsymbol{A}_{\mathrm{H}}$ & - \\
Usable zone $\boldsymbol{A}_{\mathrm{U}}$ & $\mathrm{M}(3)$ \\
Replaced zone $\boldsymbol{A}_{\mathrm{R}}$ & $\mathrm{M} \mathrm{(4)}$ \\
Abandoned zone $\boldsymbol{A}_{\mathrm{F}}$ & $\mathrm{M} \mathrm{(4)}$ \\
\hline
\end{tabular}

\subsection{Over-discharge protection}

According to the vehicle status, over-discharge protection is further divided into two conditions: protection in driving mode and protection in parking mode. The protection management in driving mode is displayed in Table 4.
Table 4. Battery over-discharge protection in driving mode.

\begin{tabular}{cc}
\hline Functional state $\hat{S}_{\mathrm{C}}$ & Protection management \\
\hline Unknown state $\boldsymbol{S}_{\mathrm{X}}$ & $\mathbf{C}\left[F_{\mathrm{T}}\left(U_{\mathrm{N}}\right)\right]$ \\
\hline Fully charged state $\boldsymbol{S}_{\mathrm{F}}$ & - \\
\hline Recycling zone $\hat{\boldsymbol{S}}_{\mathrm{R}}$ & - \\
\hline Transition zone $\hat{S}_{\mathrm{C}}$ & $\mathbf{C}\left[F_{\mathrm{T}}\left(U_{\mathrm{N}}\right)\right]$ \\
\hline Protection zone $\hat{S}_{\mathrm{P}}$ & $\mathbf{C}\left[F_{\mathrm{T}}\left(U_{\mathrm{H}}\right)\right], \mathbf{D}(4), \mathbf{M}(1)$ \\
\hline Start-up zone $\hat{S}_{\mathrm{L}}$ & $\mathbf{C}\left[F_{\mathrm{T}}\left(U_{\mathrm{H}}\right)\right], \mathbf{D}(5), \mathbf{M}(1)$ \\
\hline
\end{tabular}

If the charging voltage is $U_{\mathrm{N}}$ at a standard temperature, considering the battery temperature characteristics, the charging voltage at temperature $T$ is modified as follows: $F_{\mathrm{T}}\left(U_{\mathrm{N}}\right)=U_{\mathrm{N}}-k_{\mathrm{T}}\left(T-T_{0}\right)$,

where $k_{\mathrm{T}}$ is the temperature correction coefficient, determined by experiments or experience.

In general, the battery functional state will not descend into the protection or start-up zones while the engine is running to promote the power generation, unless a failure occurs. Therefore, when the battery is in the protection or start-up zones, a warning message needs to be sent to the driver to check the failure, as indicated in Table 4. Moreover, a restriction for EEDs is executed to ensure that the vehicle can reach $4 \mathrm{~S}$ stores for treatment.

When the vehicle is parked, the battery cannot be charged, and over-discharge protection mainly depends on the discharge limitation. For different battery states, proper limitation grades for over-discharge protection are triggered, as indicated in Table 5. When the battery is in the protection or start-up zone, an additional warning message is sent out to warn the driver to run the engine as soon as possible.

Table 5. Battery over-discharge protection in parking mode.

\begin{tabular}{cc}
\hline Functional state $\hat{S}_{\mathrm{C}}$ & Protection management \\
\hline Unknown state $\boldsymbol{S}_{\mathrm{X}}$ & $\mathbf{D}(1)$ \\
\hline Fully charged state $\boldsymbol{S}_{\mathrm{F}}$ & - \\
\hline Recycling zone $\hat{\boldsymbol{S}}_{\mathrm{R}}$ & $\mathbf{D}(2)$ \\
\hline Transition zone $\hat{\boldsymbol{S}}_{\mathrm{C}}$ & $\mathbf{D}(3)$ \\
\hline Protection zone $\hat{\boldsymbol{S}}_{\mathrm{P}}$ & $\mathbf{D}(4), \mathbf{M}(2)$ \\
\hline Start-up zone $\hat{\boldsymbol{S}}_{\mathrm{L}}$ & $\mathbf{D}(5), \mathbf{M}(2)$ \\
\hline
\end{tabular}

\subsection{Graded over-current protection}

Over-current protection for the electric power supply is of vital importance to battery health and driving safety. According to the conditions of the measured and rated current, the over-current status can be divided into five zones, as illustrated in Fig. 4, where $I_{\mathrm{M}}$ is the measured current, $I_{\mathrm{R}}$ is the rated current, and $k_{1}, k_{2}$, and $k_{3}$ are defined parameters: $0<k_{1}<1<k_{2}<k_{3}$. 


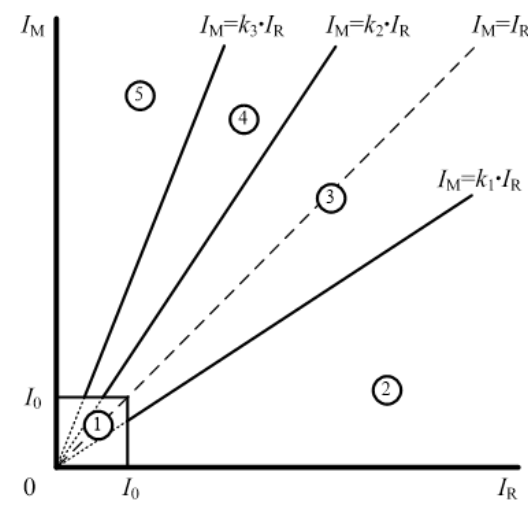

Figure 4. Over-current status diagram.

In zone 1 , when $I_{\mathrm{M}}$ and $I_{\mathrm{R}}$ are both lower than $I_{0}$ which is pretty small, it is not possible to determine the overcurrent status, owing to the current measurement error and inaccuracy. Hence, in zone 1, the power supply is considered as safe. In zone 2, the over-current status is judged to be lower than expected, in which case a warning is sent out to alert the driver to check the connections. In zone 3, the over-current status is judged to be functioning normally. In zone 4 , the over-current status is judged to be a weak over-current, and a warning is sent out requiring a system examination. In zone 5 , the over-current status is judged as severe over-current, and a delayed cutoff command is executed when the engine is not launched.

According to the study of Karegar [36], in zone 5, the delay time is designed according to the degree of overcurrent failure, as illustrated in Fig. 5. The relationship between delay time $t$ and overload ratio $k\left(I_{\mathrm{M}} / I_{\mathrm{R}}\right)$ can be expressed as follows:

$k^{\sigma} \cdot t=k_{3}^{\varpi} \cdot t_{3}, k \geq k_{3}$,

where $\varpi$ is a parameter normally set between 2 and 5 .

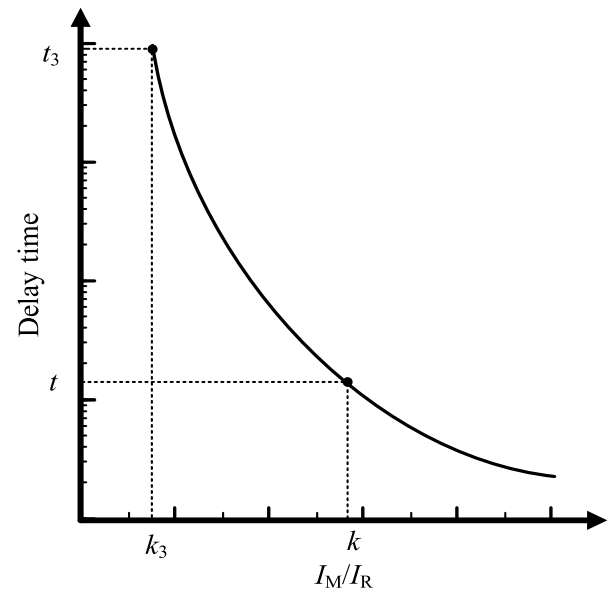

Figure 5. Cutoff delay time for severe over-current failure.

\section{MODEL-BASED ENERGY MANAGEMENT STRATEGY}

At present, working mode of generator is relatively simple, and energy optimization management considering battery security and vehicle power performance is difficult to achieve. In this section, multiple working modes of generator are developed, following which energy management strategy based on AAFSM is studied in order to realize energy optimization under the premise of ensuring start-up capability and vehicle power performance.

5.1. Multiple working modes of generator

Multiple working modes of the generator signify multiple output voltage, which provide a foundation for energy optimization management. The generator working modes are specifically described as follows.

1) Normal charge mode: as with the traditional working status, the generator output voltage is generally rated, which is $U_{\mathrm{N}}$ at a standard temperature.

2) Quick charge mode: if the battery is low, the generator output voltage is increased to charge the battery rapidly, which is $U_{\mathrm{H}}$ at a standard temperature.

3) Recovery mode: the generator output voltage is increased when the vehicle is braking in order to improve the energy recovery performance, which is $U_{\mathrm{R}}$ at a standard temperature.

4) Floating charge mode: the generator output voltage is reduced to charge the battery in floating mode, which is $U_{\mathrm{F}}$ at a standard temperature.

5) Off mode: the excitation current of the generator is cut down, the generator is turned off or idling, and the engine fuel consumption is reduced.

As per the design of the experimental vehicle, $U_{\mathrm{F}}<U_{\mathrm{N}}$ $<U_{\mathrm{H}}<U_{\mathrm{R}}$. These parameters reflect the values at a standard temperature, and in practical applications, the voltage needs to be adjusted according to Eq. (12).

\subsection{Energy management strategy}

Based on multiple working modes of the generator and AAFSM of the battery, a practical and realizable energy management strategy is established, as indicated in Table 6. The generator working modes are dynamically adjusted according to the vehicle status and battery state. Table 6. Energy management strategy.

\begin{tabular}{|c|c|c|c|c|c|}
\hline $\begin{array}{l}\text { Kehicle status } \\
\text { Battery state }\end{array}$ & $\begin{array}{l}\text { Start- } \\
\text { up }\end{array}$ & $\begin{array}{c}\text { Idling/ } \\
\text { Constant }\end{array}$ & Braking & $\begin{array}{l}\text { Accelera } \\
\text { ting }\end{array}$ & Parking \\
\hline $\begin{array}{c}\text { Unknown state } \\
\boldsymbol{S}_{\mathrm{X}}\end{array}$ & Off & Normal & Recovery & Floating & Off \\
\hline $\begin{array}{c}\text { Fully charged } \\
\text { state } S_{\mathrm{F}}\end{array}$ & Off & Off & Floating & Off & Off \\
\hline$\underset{\hat{\boldsymbol{S}}_{\mathrm{R}}}{\operatorname{Recycling} \text { zone }}$ & Off & Off & Recovery & Off & Off \\
\hline $\begin{array}{c}\text { Transition zone } \\
\hat{\boldsymbol{S}}_{\mathrm{C}}\end{array}$ & Off & $\begin{array}{c}\text { Off / } \\
\text { normal }\end{array}$ & Recovery & Off & Off \\
\hline $\begin{array}{c}\text { Protection zone } \\
\hat{\boldsymbol{S}}_{\mathrm{P}}\end{array}$ & Off & Normal & Recovery & Floating & Off \\
\hline Start-up zone $\hat{S}_{\mathrm{L}}$ & Off & Rapid & Recovery & Rapid & Off \\
\hline
\end{tabular}


When the engine is being cranked for start-up, the generator is in off mode to not increase the battery starting load; then, the battery is fully served for the starting.

When the vehicle is braking, the generator is set to recovery mode, thereby recovering the braking energy with high power. Only when the battery is fully charged, the generator switches to the floating charge mode in order to preserve battery health.

When the vehicle is accelerating and the battery charge is sufficient, the generator is set to off mode in order to enhance the power performance. Once the battery is low, it is charged to prevent over-discharge.

When the vehicle maintains a constant speed and the battery charge is sufficient, the generator is set to off mode in order to reserve storage space for energy recovery. In the transition zone, the generator switches between the off mode and normal charge mode. If the battery charge reaches the upper limit of the transition zone, the generator switches to off mode, and to normal charge mode for the lower limit.

Regarding the proposed energy management strategy, there are several points to be noted, explained as follows.

1) The judgement of the vehicle status "start-up" depends on working state of the starter, and that of vehicle status "parking" depends on working state of the engine. When the engine stops working, the vehicle is regarded as "parking".

2) The "constantlbrakinglaccelerating" vehicle status in Table 6 is judged based on a precondition that the vehicle speed has already exceeded the set threshold. Otherwise, the generator is set to operate in the existing mode. When the vehicle is operating in heavy traffic, the vehicle is always at low speed and frequently brakes, stops, accelerates. This precondition can effectively prevent the generator from frequently switching the working mode, which may cause damage to the generator and the battery.

3) Based on the satisfactory of the precondition, the determination of "constantlbrakinglaccelerating" status depends on the combination of acceleration, brake pedal signal and the duration time, rather than solely relying on the acceleration and brake pedal signals. This can further effectively prevent the generator from frequently switching the working mode, due to the instantaneous error signals.

With the proposed energy optimization management, integrated optimization of fuel economy, battery protection, and vehicle power performance can be achieved.

\section{EXPERIMENTS AND RESULTS}

Experiments were performed on the vehicle and test bench to verify the feasibility and effectiveness of the presented AAFSM, battery protection scheme, and model-based energy management strategy.

\subsection{Tests for AAFSM}

Tests were carried out on one ICE vehicle to verify that the proposed AAFSM of battery can reflect the practical battery characteristics. A control unit which was responsible for estimating battery state based on AAFSM and achieving battery protection according to the modelbased protection scheme, was installed on the experimental vehicle, as shown in Fig. 6. A battery sensor detected the working status of battery including current, voltage, etc. Then the control unit estimated the battery state based on AAFSM, and implemented battery protection functions.

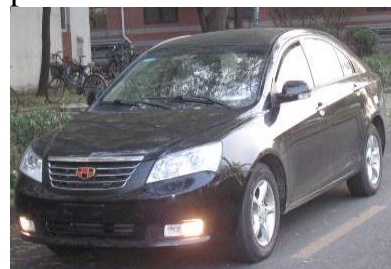

\section{(a) Experimental vehicle}

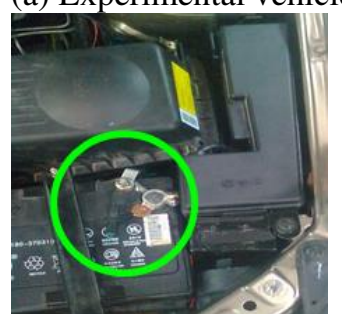

(b) battery sensor

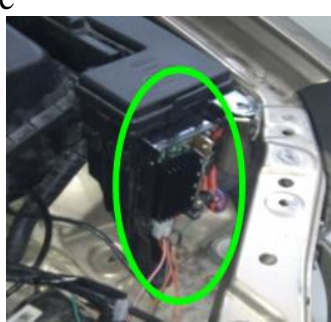

(c) control unit
Figure 6. Photos of experimental vehicle.

The experimental battery was the lead-acid battery in a healthy state, as judged by the control unit. The overdischarge protection scheme was artificially shielded in advance. The tests were designed as presented in Table 7. The engine of experimental vehicle was turned off, and then the EEDs were turned on to discharge the battery until reaching the boundary of the start-up and protection zones, which is the line $l_{1}-l_{2}$ indicated in Fig. 3. This process was executed automatically by the control unit. Thereafter, the engine was launched to test the start-up capability, as designed in step 3. The result is illustrated in Fig. 7, where it can be observed that the engine launch was tested five times, and the engine successfully launched each time. Then, step 4 was executed. After turning on the headlamp for $1 \mathrm{~min}$, the engine launch was tested again and failed, as illustrated in Fig. 8. Therefore, the result shows that the designed start-up zone can support the engine launch several times.

Table 7. Design of model tests.

\begin{tabular}{cc}
\hline Step & Operation \\
\hline 1 & Turn off engine \\
\hline 2 & $\begin{array}{c}\text { Turn on EEDs to discharge battery until reaching the boundary of } \\
\text { start-up and protection zones }\end{array}$ \\
\hline
\end{tabular}




\begin{tabular}{cc}
\hline $\mathbf{3}$ & Launch engine to test start-up capability \\
\hline 4 & Turn off engine again and discharge battery slightly \\
\hline
\end{tabular}
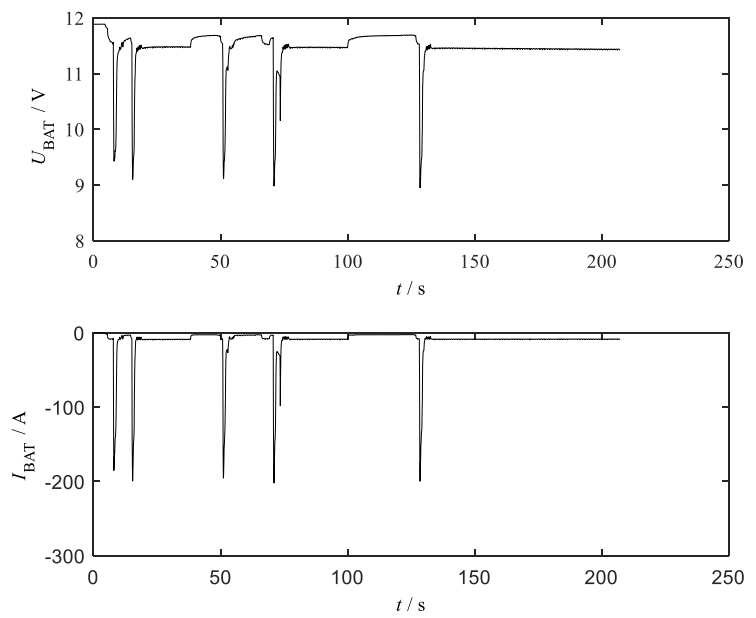

Figure 7. Engine launch test of step 3.
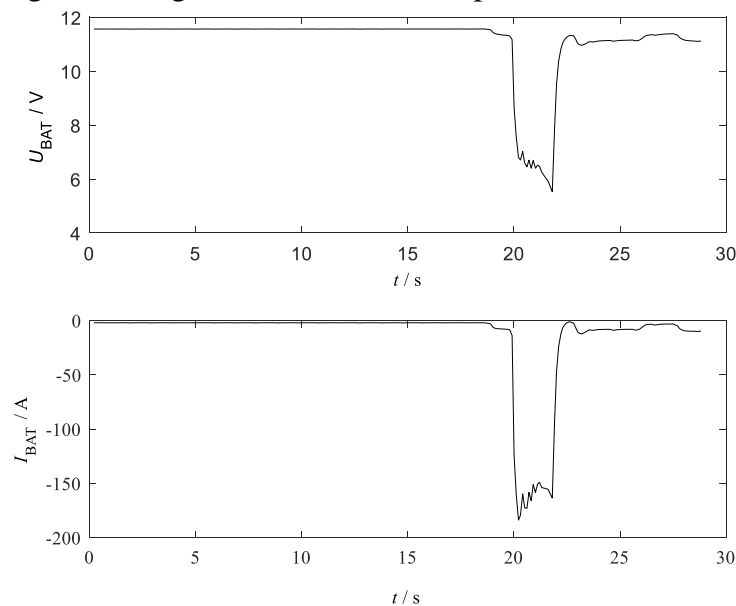

Figure 8. Engine launch test after step 4.

The start-up zone is designed to supply the electric power for the vehicle to start up. This zone is modeled to reflect the battery start-up capability, and the boundary of this zone is designed to support the engine launch several times in order to leave a margin in the control unit. It can be concluded that the proposed model can reflect the battery operating characteristics, and the model can be used for battery management.

\subsection{Tests for battery over-discharge protection}

Experiments for the battery over-discharge protection were carried out on the experimental vehicle, too. In order to verify the effectiveness, tests were performed under the most dangerous scenario, which was, the engine was turned off, and thus unable to charge the battery. The battery was fully charged beforehand, and as many EEDs as possible were turned on to consume electric power. The results are illustrated in Fig. 9.

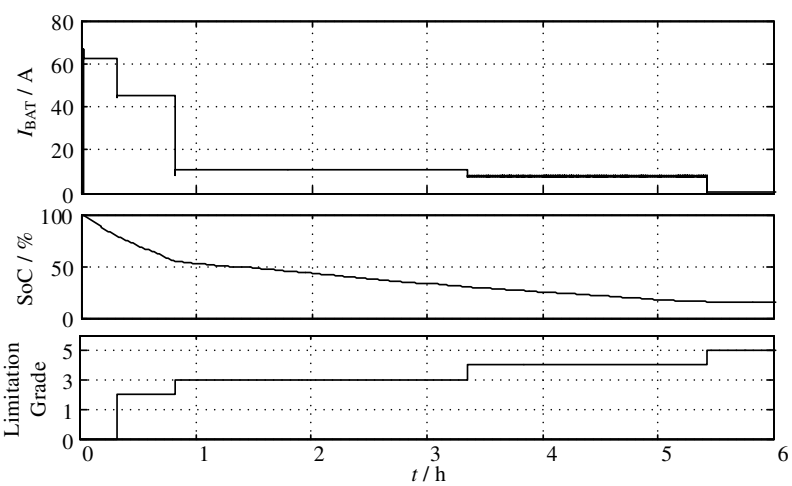

Figure 9. Test results of battery over-discharge protection on vehicle.

As illustrated in Fig. 9, different limitation grades were triggered according to the battery state, and warning messages were sent out. Seven days later, the engine launch was tested and the engine launched successfully. It can be concluded that battery over-discharge protection was achieved and start-up capability was secured.

6.3. Tests for battery over-current protection

The over-current tests were carried out on the test bench, and the connection of test equipment was shown in Fig. 10. The red lines are electric power lines and the black ones are ground lines. The control unit is able to control the electric power supply; a battery discharger is utilized as a load, with its current dynamically adjustable; a current sensor is used to measure the battery's discharging current, and a signal collector is used for analog-digital signal acquisition; $\mathrm{CANoE}$ is used to obtain warning messages sent out by the control unit.

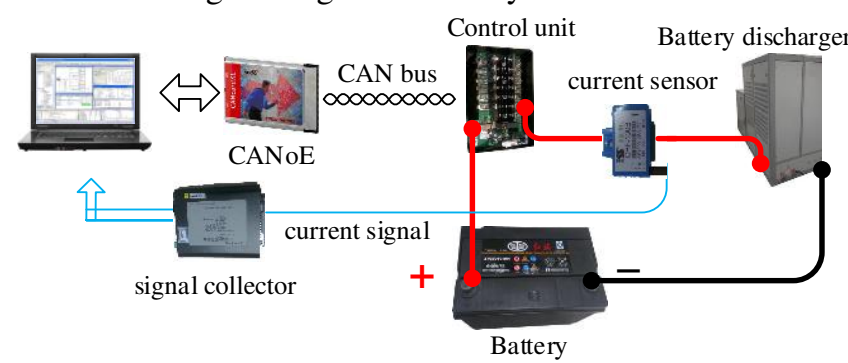

Figure 10. Equipment and their connection for battery over-current protection test.

Tests were designed as indicated in Table 8 . The rated current was set to $5 \mathrm{~A}$, while the test current was set by battery discharger to imitate the over-current status. Four different over-current states were simulated by changing the test current. The test results are illustrated in Fig. 11. Table 8. Design of over-current tests.

\begin{tabular}{ccccc}
\hline Step & $\begin{array}{c}\text { Duration } \\
(\mathrm{s})\end{array}$ & $\begin{array}{c}\text { Test current } \\
(\mathrm{A})\end{array}$ & $\begin{array}{c}\text { Rated } \\
\text { current (A) }\end{array}$ & Simulation status \\
\hline 1 & 120 & 2.9 & 5 & Current too low \\
\hline 2 & 120 & 5.0 & 5 & Functioning \\
\hline $\mathbf{3}$ & 120 & 6.8 & 5 & Weak over-current \\
\hline 4 & 120 & 14.6 & 5 & Severe over-current \\
\hline
\end{tabular}




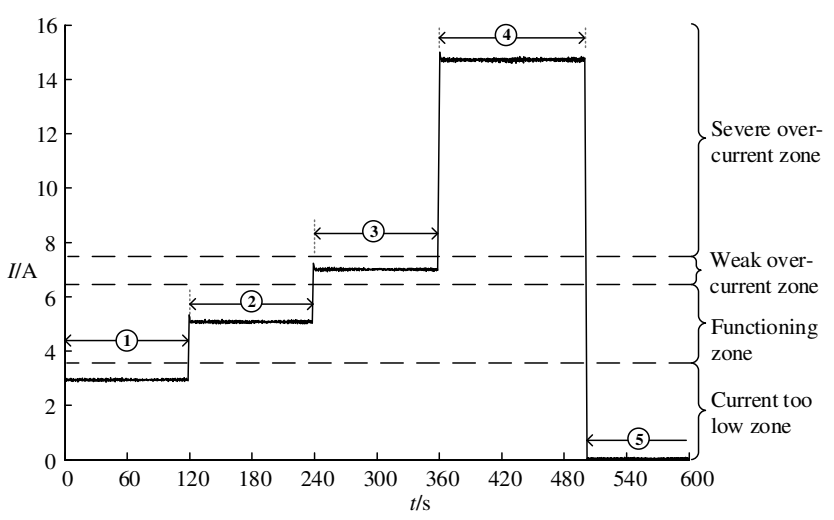

Figure 11 . Test results of battery over-current protection on test bench.

As illustrated in Fig. 11, during steps 1 to 4, corresponding warning messages were sent out to alert the driver to examine the system. In step 4, in addition to the warning message, the power supply was automatically cut off 120 s later as step 5 showed, as per the design. Therefore, over-current failure was avoided and over-current protection was achieved.

\subsection{Tests for energy management strategy}

Verification of the energy management strategy was performed by means of fuel consumption comparison tests on the ICE vehicle. Comparison tests were carried out under the same driving conditions, with the same vehicle and battery. The experimental vehicle is Geely Dorsett EC7, and the battery is lead-acid battery, Camel brand, $12 \mathrm{~V}, 60 \mathrm{Ah}$. The test condition is the national standard cycling condition illustrated in Fig. 12

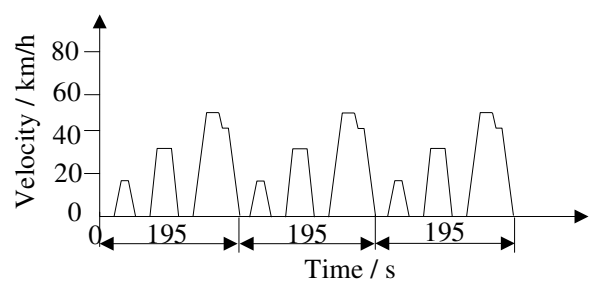

Figure 12. Standard cycling condition.

Two same vehicles are operated according to the standard cycling condition. One is modified with energy optimization management, and the other remains the conventional system. The test duration is $600 \mathrm{~s}$, covering the whole standard cycling condition of Fig. 12. For the vehicle with energy optimization management, the battery voltage and current are illustrated in Fig. 13. The vehicle fuel consumption with the proposed management scheme is depicted in Fig. 14(a), while that with the conventional system is illustrated in Fig. 14(b). The comparison results are provided in Table 8 .
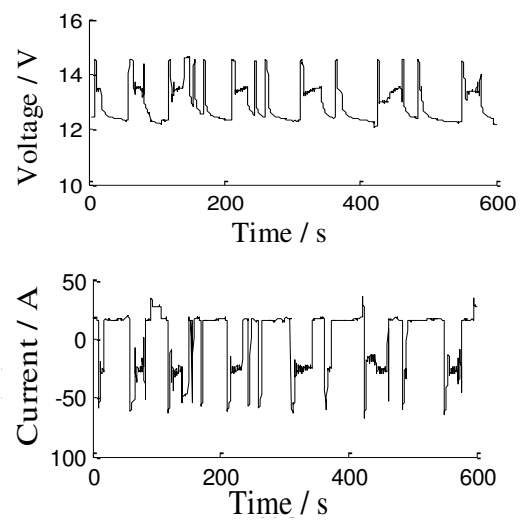

Figure 13. Battery voltage and current for vehicle with proposed management.

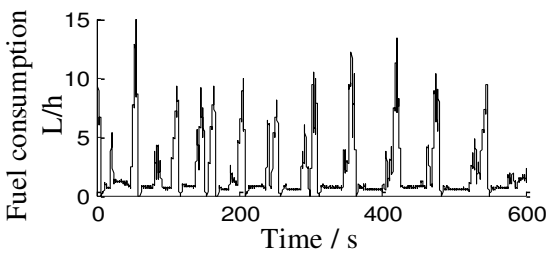

(a) vehicle with conventional management

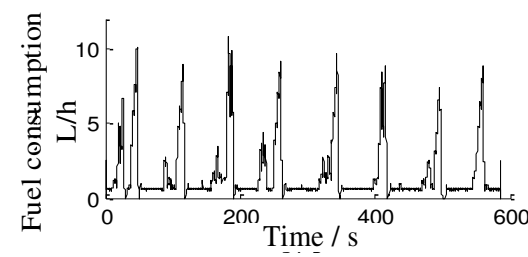

(b) vehicle with optimization system

Figure 14. Comparison of fuel consumption.

Table 9. Fuel consumption of vehicle with proposed management and conventional system.

\begin{tabular}{ccc}
\hline & $\begin{array}{c}\text { Vehicle with proposed } \\
\text { management }\end{array}$ & $\begin{array}{c}\text { Vehicle with } \\
\text { traditional system }\end{array}$ \\
\hline $\begin{array}{c}\text { Overall fuel consumption } \\
(\mathrm{L})\end{array}$ & 0.357 & 0.371 \\
\hline $\begin{array}{c}\text { Fuel consumption for } 100 \\
\mathrm{~km}(\mathrm{~L} / 100 \mathrm{~km})\end{array}$ & 10.66 & 11.07 \\
\hline
\end{tabular}

As illustrated in Fig. 13, when the vehicle was braking, the battery was charged with a voltage of $14.5 \mathrm{~V}$, and the charging current reached more than $50 \mathrm{~A}$. In this manner, the braking energy was stored in the battery. As can be observed from Table 9, the fuel consumption of the vehicle with the proposed management was $10.66 \mathrm{~L} / 100$ $\mathrm{km}$, while that with the conventional system was 11.07 $\mathrm{L} / 100 \mathrm{~km}$, and the fuel economy was increased by $3.7 \%$.

\section{CONCLUSIONS}

This paper proposes a novel battery model combining battery's actual operating conditions on vehicles with its chemical characteristics, which is the AAFSM of battery. In addition, this paper presents a model-based battery 
protection scheme, and establishes a model-based energy optimization management strategy for IVs driven by ICE.

With the AAFSM, a battery is divided into various function zones which dynamically adjust as battery ages. Incidence relationship between the functional and aging states is elaborated. Battery functional characteristics covering the full life cycle are presented. Battery aging zones are proposed, revealing different aging stages of battery from the perspective of practical applications. AAFSM comprehensively reveals the battery characteristics for IVs driven by ICE in its practical applications, providing a valuable and practical research direction for battery management.

The model-based battery protection scheme can protect the battery from over-discharge and over-current failure. For different over-current grades, different protection measures are implemented. The start-up capability is effectively secured, and the electric power supply safety can be achieved.

Instead of the conventional working mode of a generator on ICE vehicles, multiple working modes are established. Then energy management strategy is studied, selecting the optimal working mode of the generator according to the battery state and vehicle status. Fuel economy can be effectively improved under the premise of ensuring start-up capability and vehicle power performance.

Tests are performed on the vehicle and test bench to verify the validity and feasibility of the proposed model and management scheme. The results reveal that the model can reflect battery operating features, over-current protection and over-discharge protection of the battery are achieved, and the vehicle start-up capability is secured. With the comparative tests on vehicles, the proposed energy management strategy can effectively improve the fuel economy.

\section{DECLARATION}

\section{Acknowledgements \\ Not applicable}

\section{Funding}

Supported by National Natural Science Foundation of China (Grant No. 52002209).

\section{Availability of data and materials}

The datasets supporting the conclusions of this article are included within the article.

\section{Authors' contributions}

The author' contributions are as follows: Weiwei Kong and Fachao Jiang were in charge of the whole trial; Weiwei Kong wrote the manuscript; Yugong Luo assisted with the modeling; Xiaomin Lian assisted with energy management and vehicle experiments.

\section{Competing interests}

The authors declare no competing financial interests.

\section{Consent for publication}

Not applicable

Ethics approval and consent to participate

Not applicable

\section{REFERENCES}

[1] Yang D G, Kong W W, Li B, et al. Intelligent vehicle electrical power supply system with central coordinated protection. Chinese Journal of Mechanical Engineering, 2016, 29(4): 781-791.

[2] Kassakian J G. Automotive electrical systems-the power electronics market of the future. Applied Power Electronics Conference and Exposition, 2000, 1:3-9.

[3] Hasenjäger $M$, Wersing $H$. Personalization in advanced driver assistance systems and autonomous vehicles: A review. IEEE International Conference on Intelligent Transportation Systems, 2017, 1-7.

[4] Barillas J K, Li J, Günther C, et al. A comparative study and validation of state estimation algorithms for Li-ion batteries in battery management systems. Applied Energy, 2015, 155:455-462.

[5] Ren H B, Zhao Y Z, Chen S Z, Wang T P. Design and implementation of a battery management system with active charge balance based on the SOC and SOH online estimation. Energy, 2019, 166:908-917.

[6] Deng Z W, Yang L, Deng H, et al. Polynomial approximation pseudo-two-dimensional battery model for online application in embedded battery management system. Energy, 2018, 142:838-850.

[7] Hannan M A, Lipu M S H, Hussain A, et al. A review of lithium-ion battery state of charge estimation and management system in electric vehicle applications: Challenges and recommendations. Renewable \& Sustainable Energy Reviews, 2017, 78:834-854.

[8] Sun F, Xiong R, He H. A systematic state-of-charge estimation framework for multi-cell battery pack in electric vehicles using bias correction technique. Applied Energy, 2016, 162:1399-1409.

[9] Yu Q Q, Rui X, Wang L Y, et al. A comparative study on open circuit voltage models for Lithium-ion batteries. Chinese Journal of Mechanical Engineering, 2018, 31(1): 65.

[10] Jinpeng Tian, Rui Xiong, Shen Weixiang, et al. A Comparative Study of Fractional Order Models on State of Charge Estimation for Lithium Ion Batteries. Chinese Journal of Mechanical Engineering, 2020, 33:51. 
[11] Zhao J , Zhang X , Rao Z . Oscillating Heat Pipe Coupled with Phase Change Material (OHP/PCM) Used for Battery Thermal Management. Journal of Beijing Institute of Technology (English Edition), 2017, 26:181-186.

[12] Siddique A R, Mahmud S, Van Heyst B. A comprehensive review on a passive (phase change materials) and an active (thermoelectric cooler) battery thermal management system and their limitations. Journal of Power Sources, 2018, 401:224-237.

[13] Liu F, Lan F, et al. Experimental Investigation on Cooling/Heating Characteristics of Ultra-Thin Micro Heat Pipe for Electric Vehicle Battery Thermal Management. Chinese Journal of Mechanical Engineering, 2018, 31(3):179-188.

[14] Cui Y Z, Zuo P J, Du C Y, et al. State of health diagnosis model for lithium ion batteries based on real-time impedance and open circuit voltage parameters identification method. Energy, 2017, 144:647-656.

[15] Pan H H, Lu Z Q, Lin W L, et al. State of charge estimation of lithium-ion batteries using a grey extended Kalman filter and a novel open-circuit voltage model. Energy, 2017, 138:764-775.

[16] Weng C, Sun J, Peng H. A unified open-circuitvoltage model of lithium-ion batteries for state-ofcharge estimation and state-of-health monitoring. Journal of Power Sources, 2014, 258(14):228-237.

[17] Chemali E, Kollmeyer P J, Preindl M, et al. Stateof-charge estimation of Li-ion batteries using deep neural networks: A machine learning approach. Journal of Power Sources, 2018, 400:242-255.

[18] Xia B Z, Cui D Y, Sun Z, et al. State of charge estimation of lithium-ion batteries using optimized Levenberg-Marquardt wavelet neural network. Energy, 2018, 153: 694-705.

[19] Chaoui H, Chinemerem C I. State of charge and state of health estimation for Lithium batteries using recurrent neural networks. IEEE Transactions on Vehicular Technology, 2017, 66:8773-8783.

[20] Burgos C, Sáez D, Orchard M E, et al. Fuzzy modelling for the state-of-charge estimation of leadacid batteries. Journal of Power Sources, 2015, 274:355-366

[21] Klass V, Behm M, Lindbergh G. A support vector machine-based state-of-health estimation method for lithium-ion batteries under electric vehicle operation. Journal of Power Sources, 2014, 270(3):262-272.

[22] Li Y W, Wang C, Gong J F. A multi-model probability SOC fusion estimation approach using an improved adaptive unscented Kalman filter technique. Energy, 2017, 141: 1402-1415.

[23] Li Y W, Wang C, Gong J F. A combination Kalman filter approach for State of Charge estimation of lithium-ion battery considering model uncertainty. Energy, 2016, 109: 933-946.

[24] Lim K C, Bastawrous H A, Duong V H, et al. Fading Kalman filter-based real-time state of charge estimation in $\mathrm{LiFePO}_{4}$ battery-powered electric vehicles. Applied Energy, 2016, 169:40-48.

[25] Shashank A. Selection of thermal management system for modular battery packs of electric vehicles: A review of existing and emerging technologies. Journal of Power Sources, 2018, 400:621-640.

[26] Bai F F, Chen M B, Song W J, et al. Investigation of thermal management for lithium-ion pouch battery module based on phase change slurry and mini channel cooling plate. Energy, 2019, 167:561-574.

[27] Saw L H, Poon H M, Hui S T, et al. Novel thermal management system using mist cooling for lithiumion battery packs. Applied Energy, 2018, 223:146158.

[28] Situ W F, Zhang G Q, Li X X, et al. A thermal management system for rectangular LiFePO4 battery module using novel double copper mesh-enhanced phase change material plates. Energy, 2017, 141:613623.

[29] Imtiaz A M, Khan F H, Kamath H. A low-cost time shared cell balancing technique for future lithium-ion battery storage system featuring regenerative energy distribution. Applied Power Electronics Conference and Exposition. IEEE, 2011:792-799.

[30] Wang J, Nan J, Xu X, et al. Power Battery Balancing Strategy of Electric Vehicle Based on Adaptive Algorithm. Journal of Beijing Institute of Technology (English Edition), 2017, 26:21-27.

[31] Daowd M, Omar N, Bossche P V D, et al. Passive and active battery balancing comparison based on MATLAB simulation. Vehicle Power and Propulsion Conference. IEEE, 2011:1-7.

[32] Forgez C, Do D V, Friedrich G, et al. Thermal modeling of a cylindrical $\mathrm{LiFePO}_{4} /$ graphite lithiumion battery. Journal of Power Sources, 2010, 195(9):2961-2968.

[33] Guo G, Long B, Cheng B, et al. Three-dimensional thermal finite element modeling of lithium-ion battery in thermal abuse application. Journal of Power Sources, 2010, 195(8):2393-2398.

[34] Wang X, Wang X H. Electric power supply system and its fault diagnosis. Auto Maintenance \& Repair, 2008, 5:66-67.

[35] Meissner E, Richer G. Battery monitoring and electrical energy management precondition for future vehicle electric power systems. Journal of Power Sources, 2003, 116: 79-98.

[36] Karegar H K, Abyaneh H A, Al-Dabbagh M. A flexible approach for overcurrent relay characteristics simulation. Electric Power Systems Research, 2003, 66:233-239. 
Figures

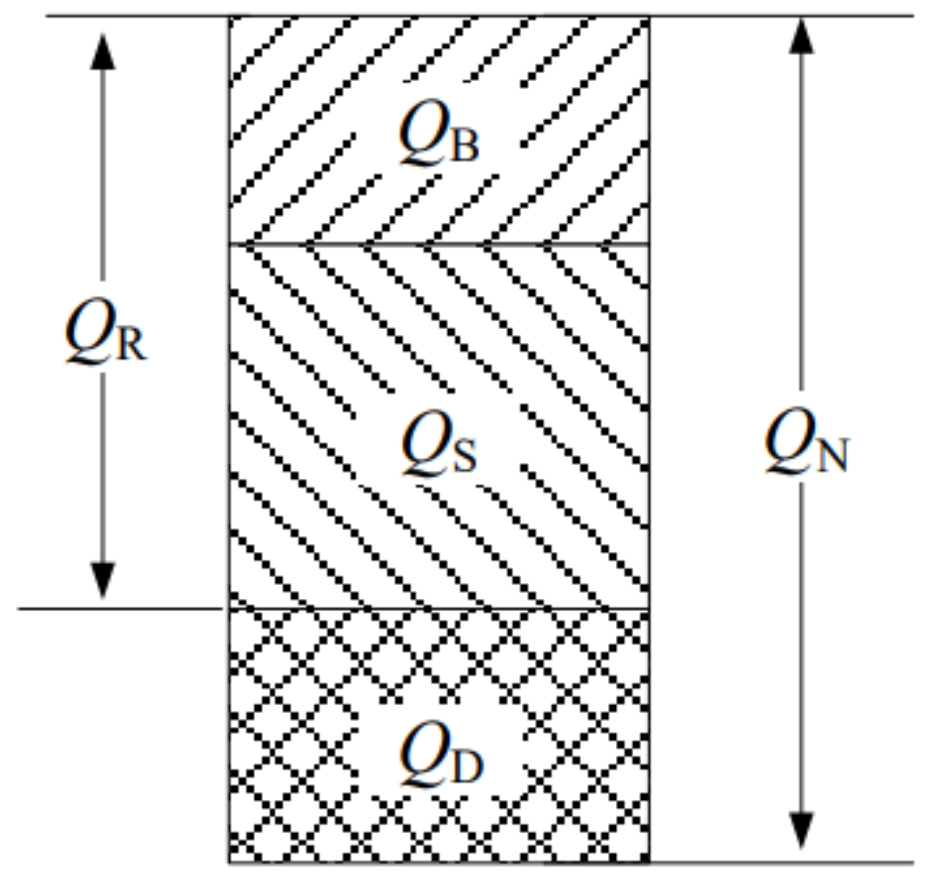

\section{Figure 1}

State variables of battery. 


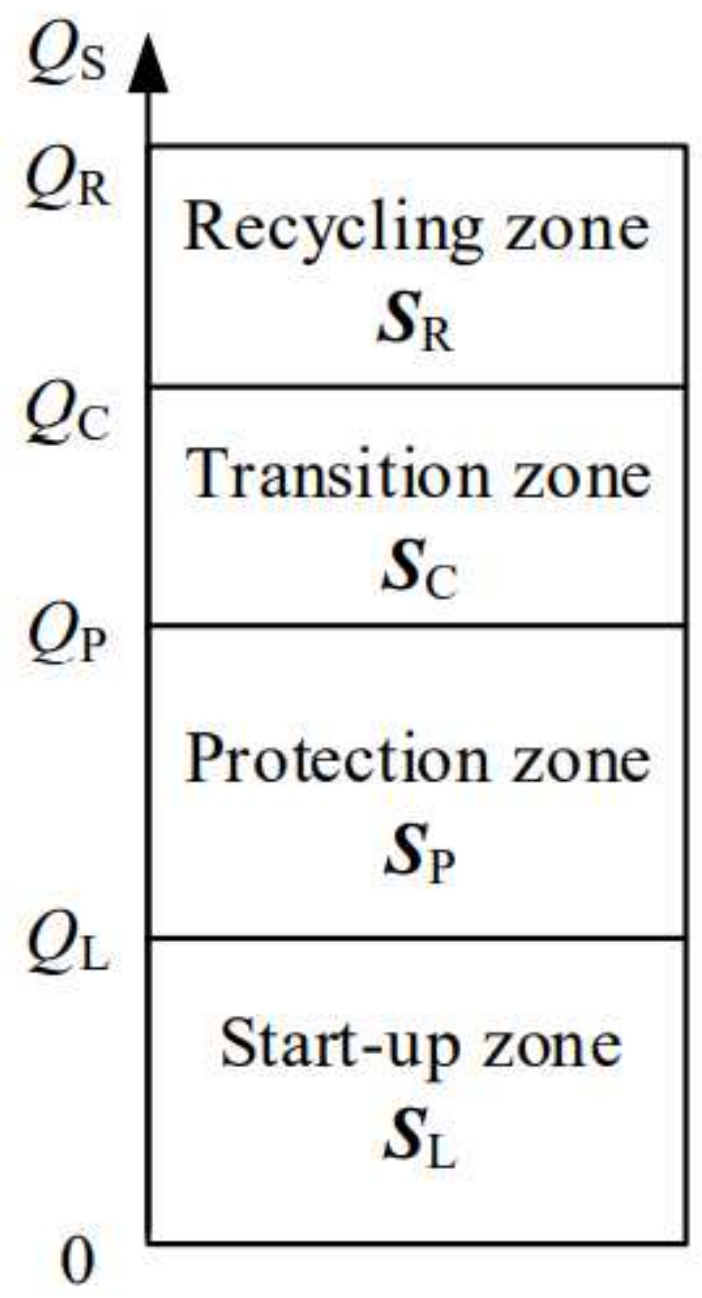

Figure 2

Function zones of battery. 


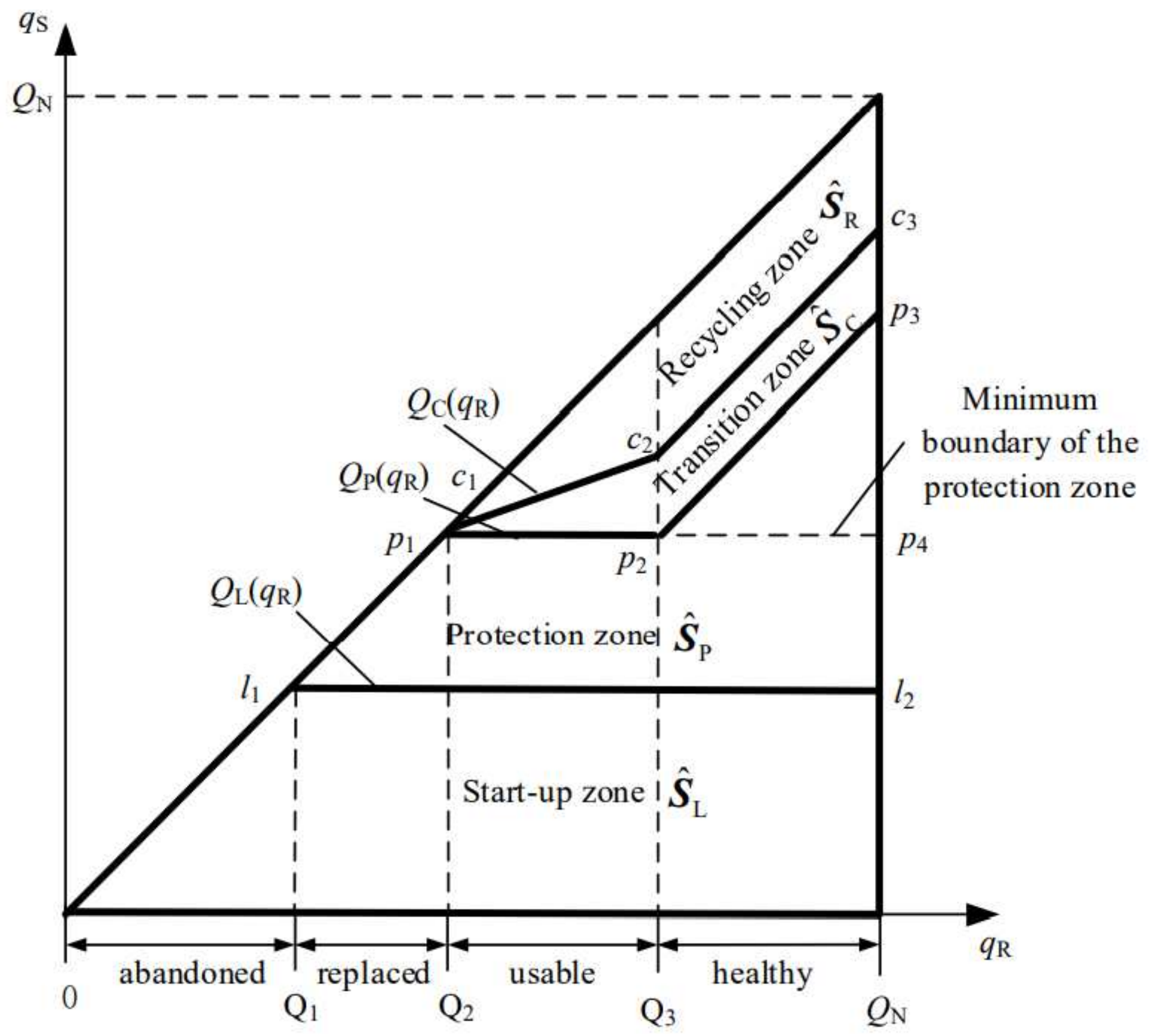

Figure 3

Battery full life cycle state space. 


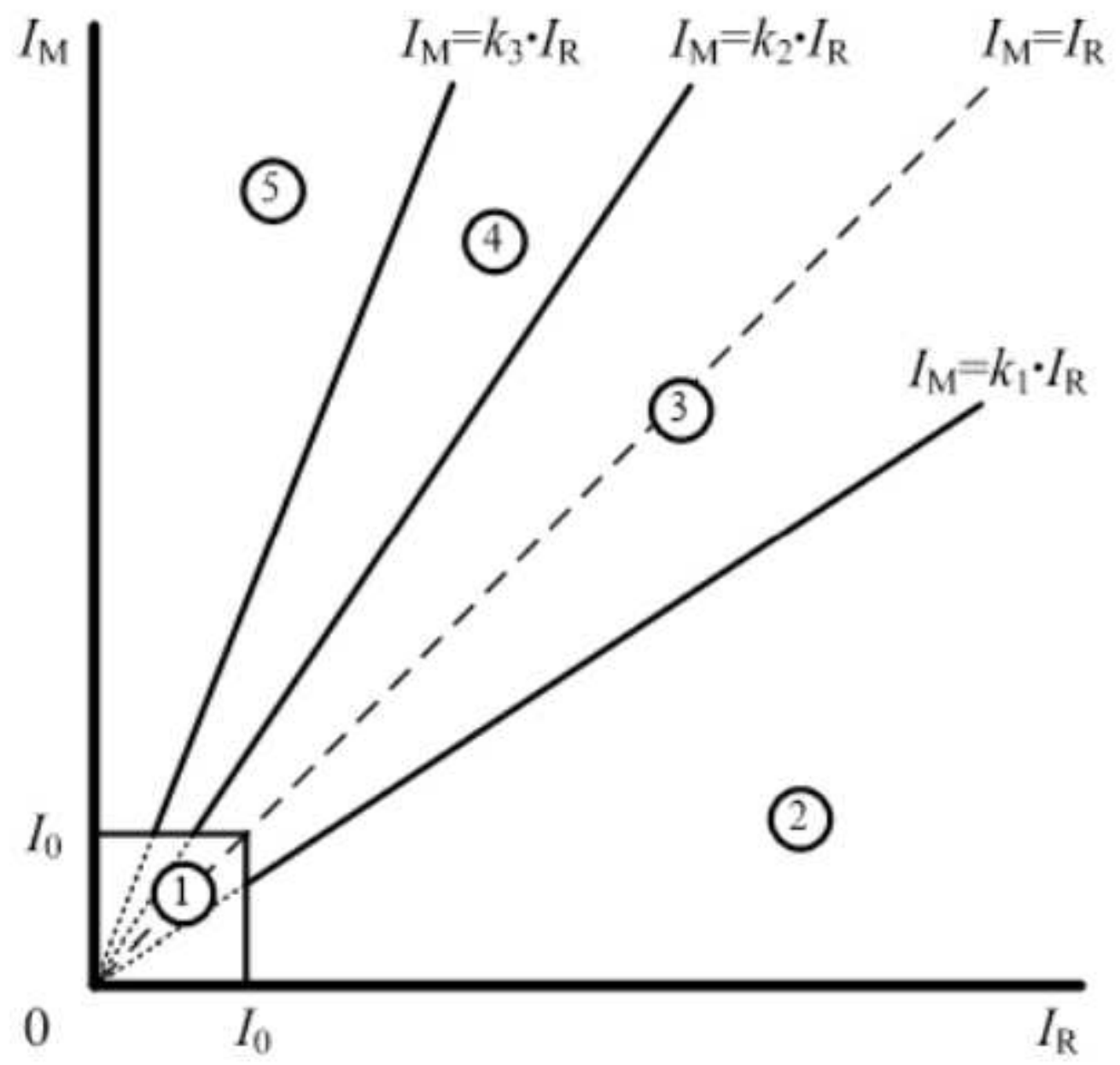

Figure 4

Over-current status diagram. 


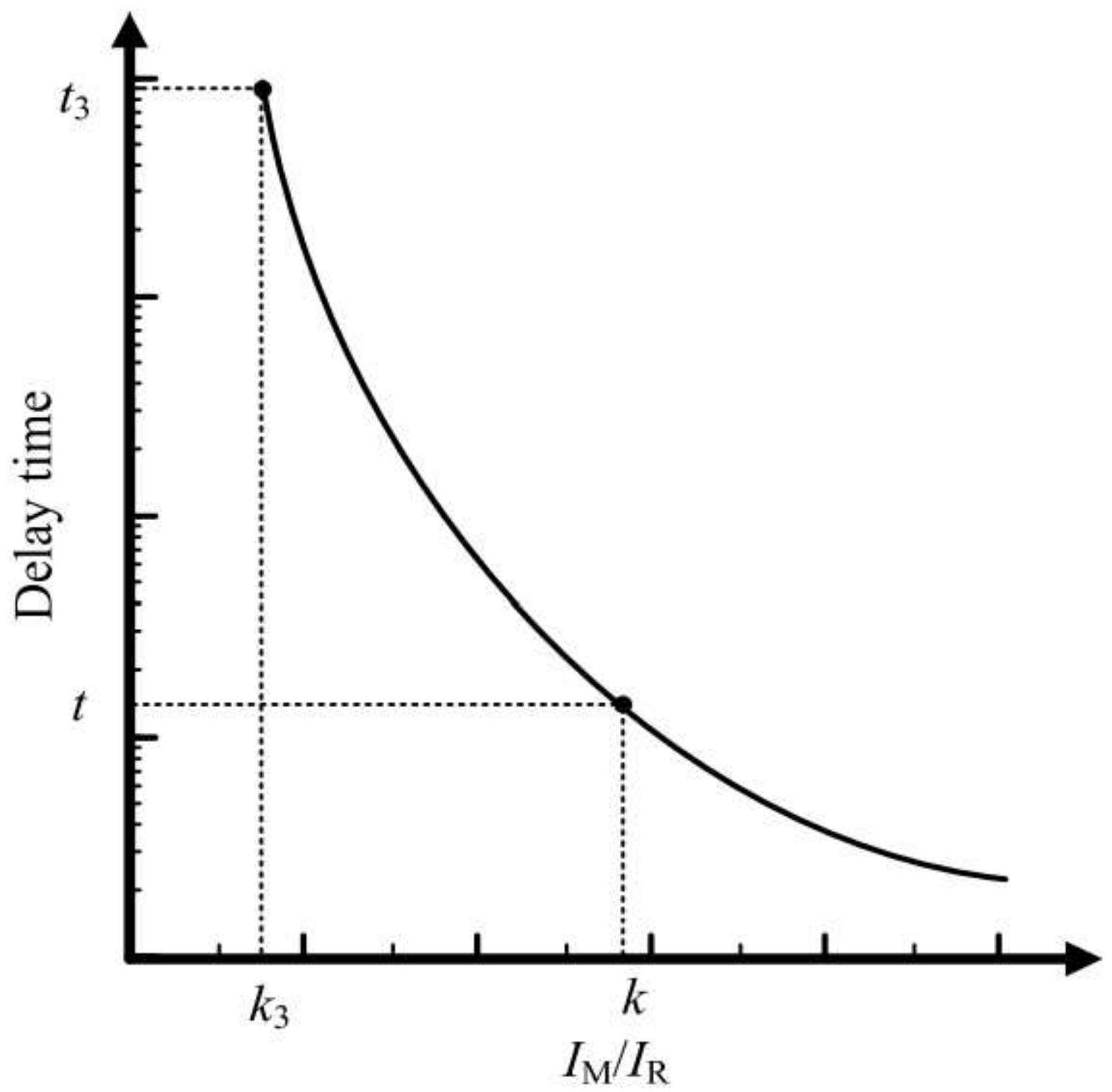

Figure 5

Cutoff delay time for severe over-current failure. 


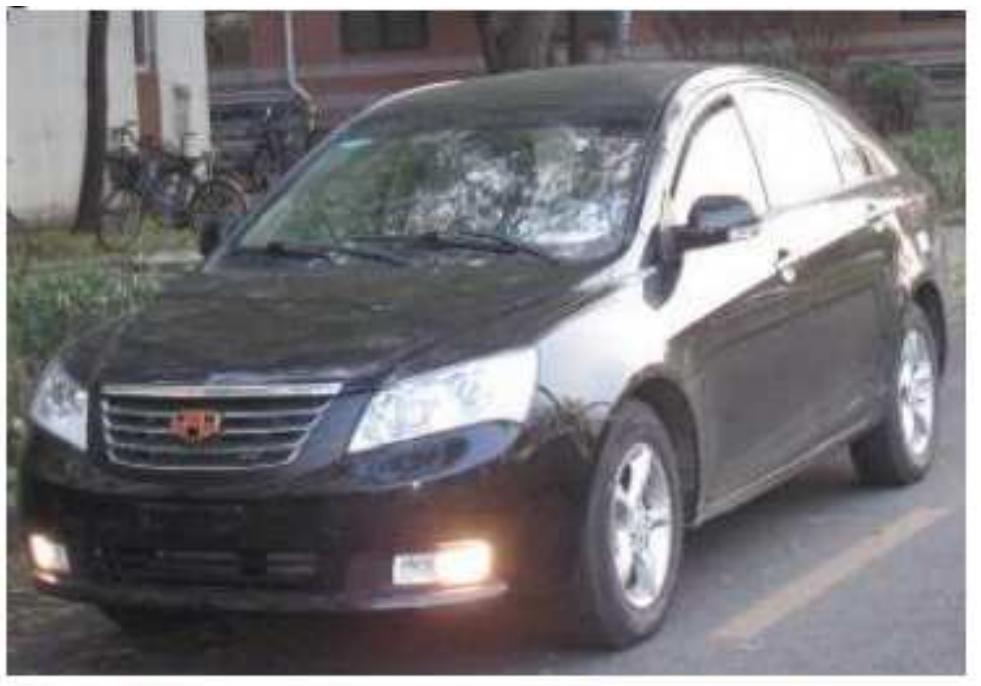

(a) Experimental vehicle

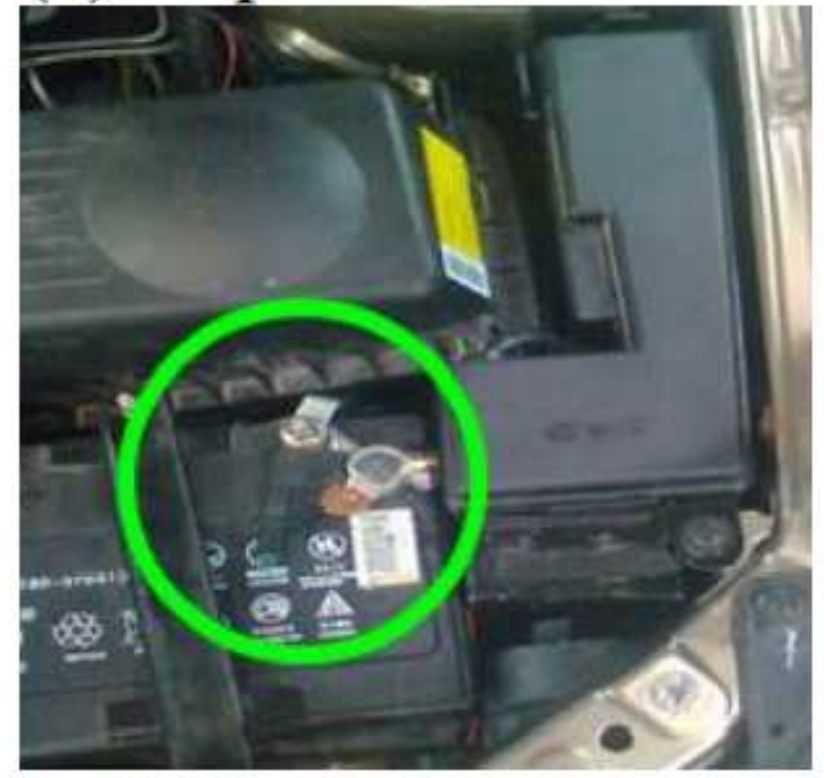

(b) battery sensor

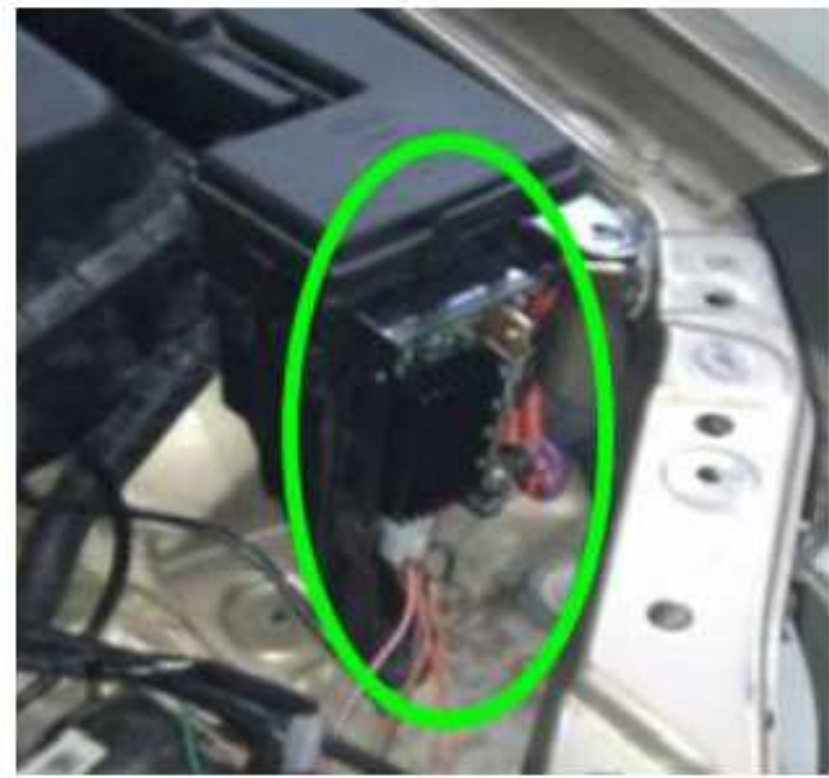

(c) control unit

Figure 6

Photos of experimental vehicle. 

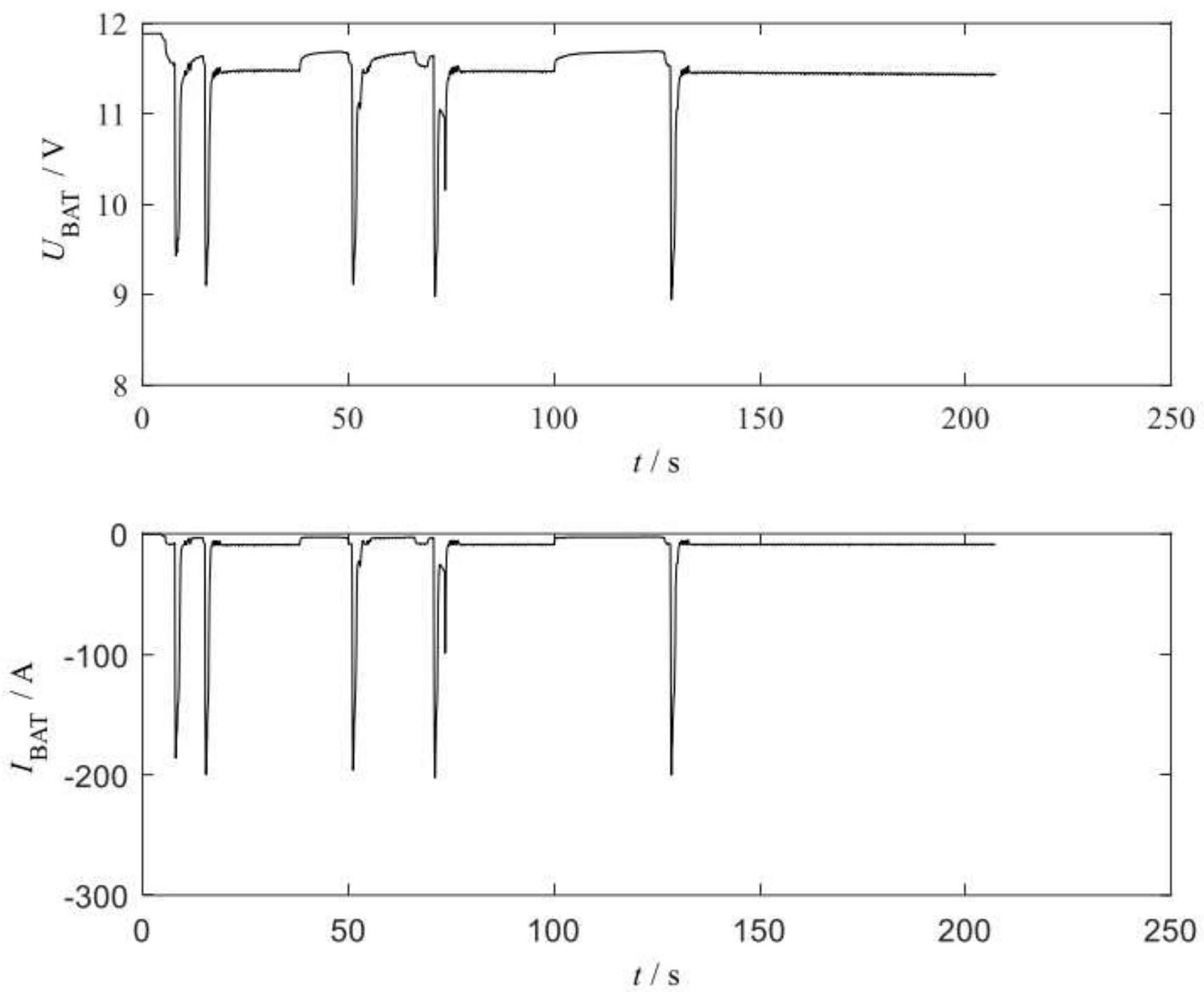

Figure 7

Engine launch test of step 3. 

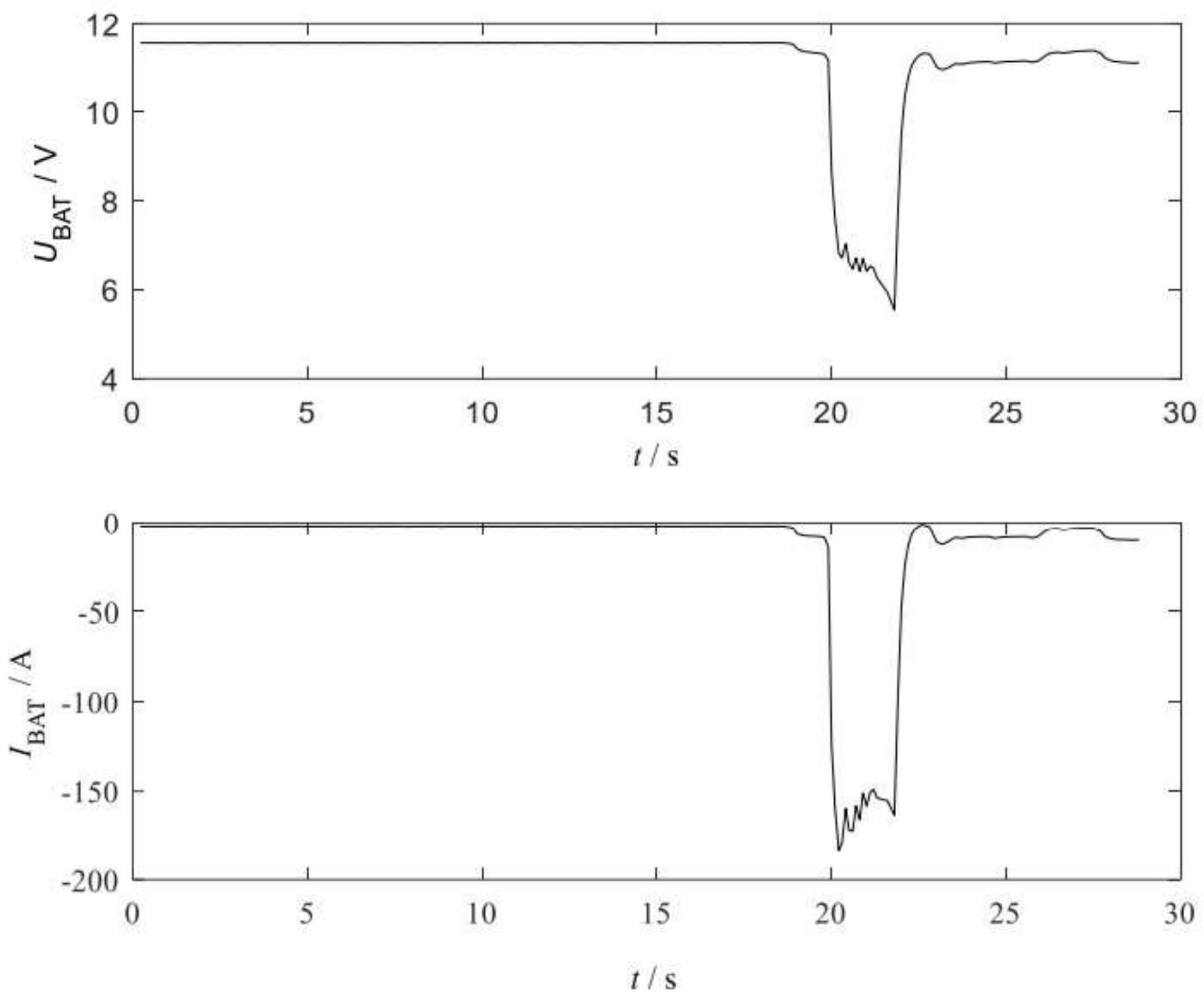

Figure 8

Engine launch test after step 4. 

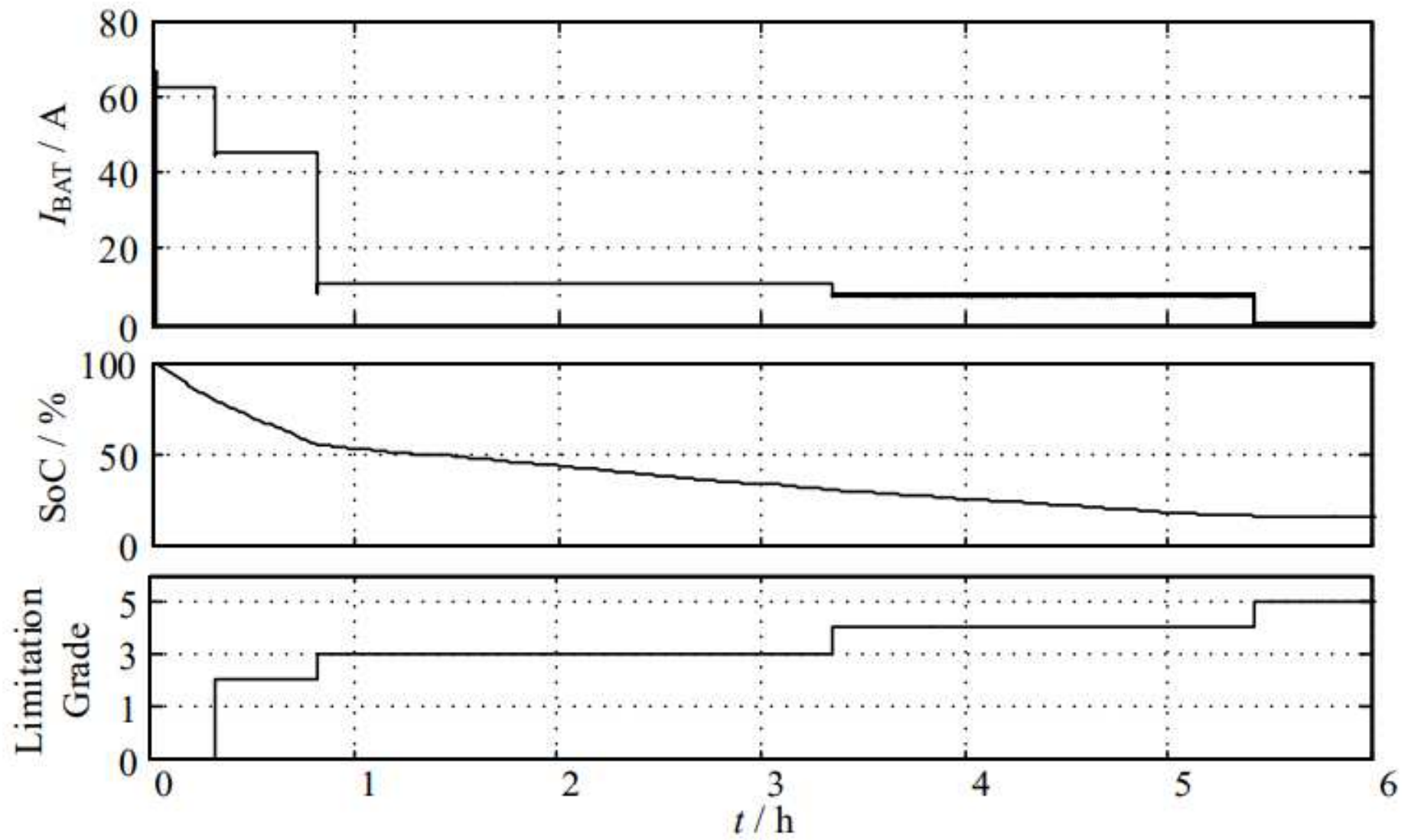

Figure 9

Test results of battery over-discharge protection on vehicle.

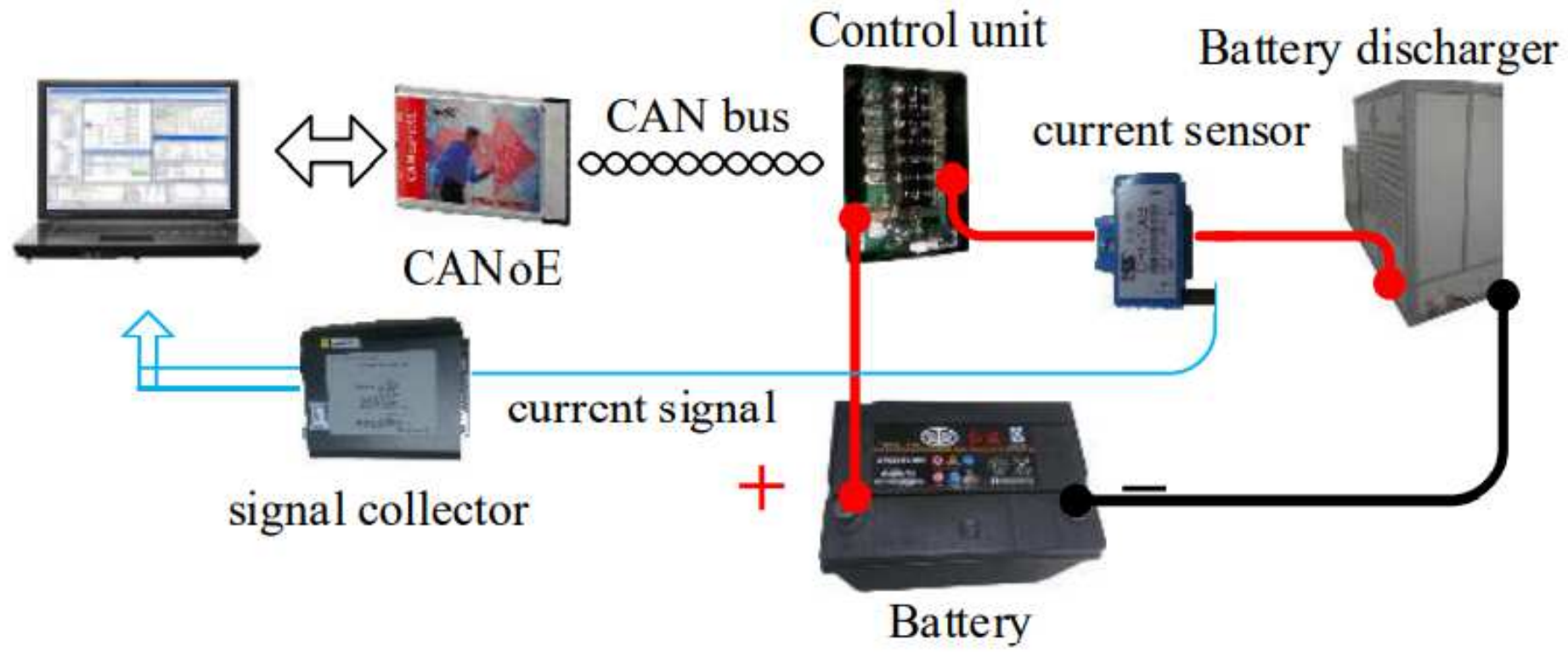

Figure 10

Equipment and their connection for battery over-current protection test. 


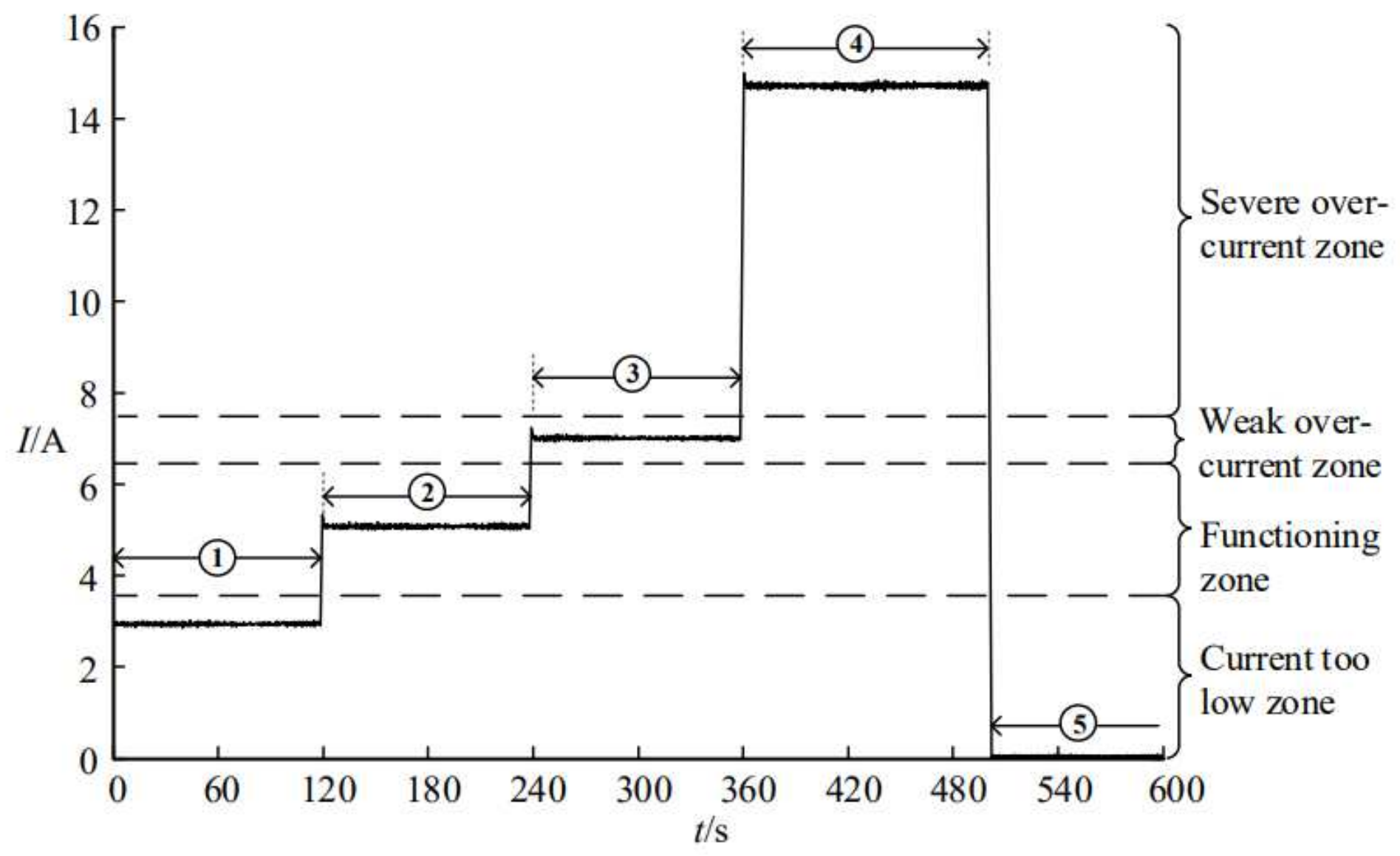

Figure 11

Test results of battery over-current protection on test bench.

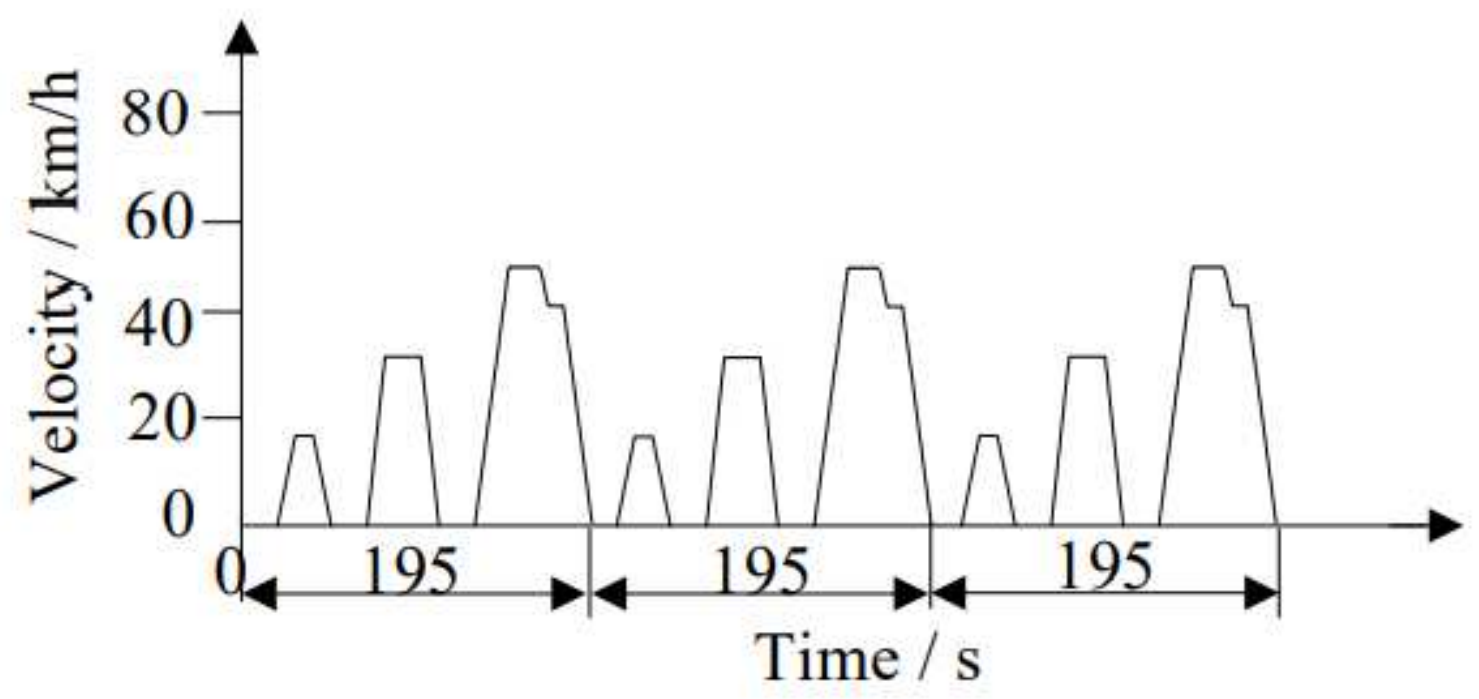

Figure 12

Standard cycling condition. 

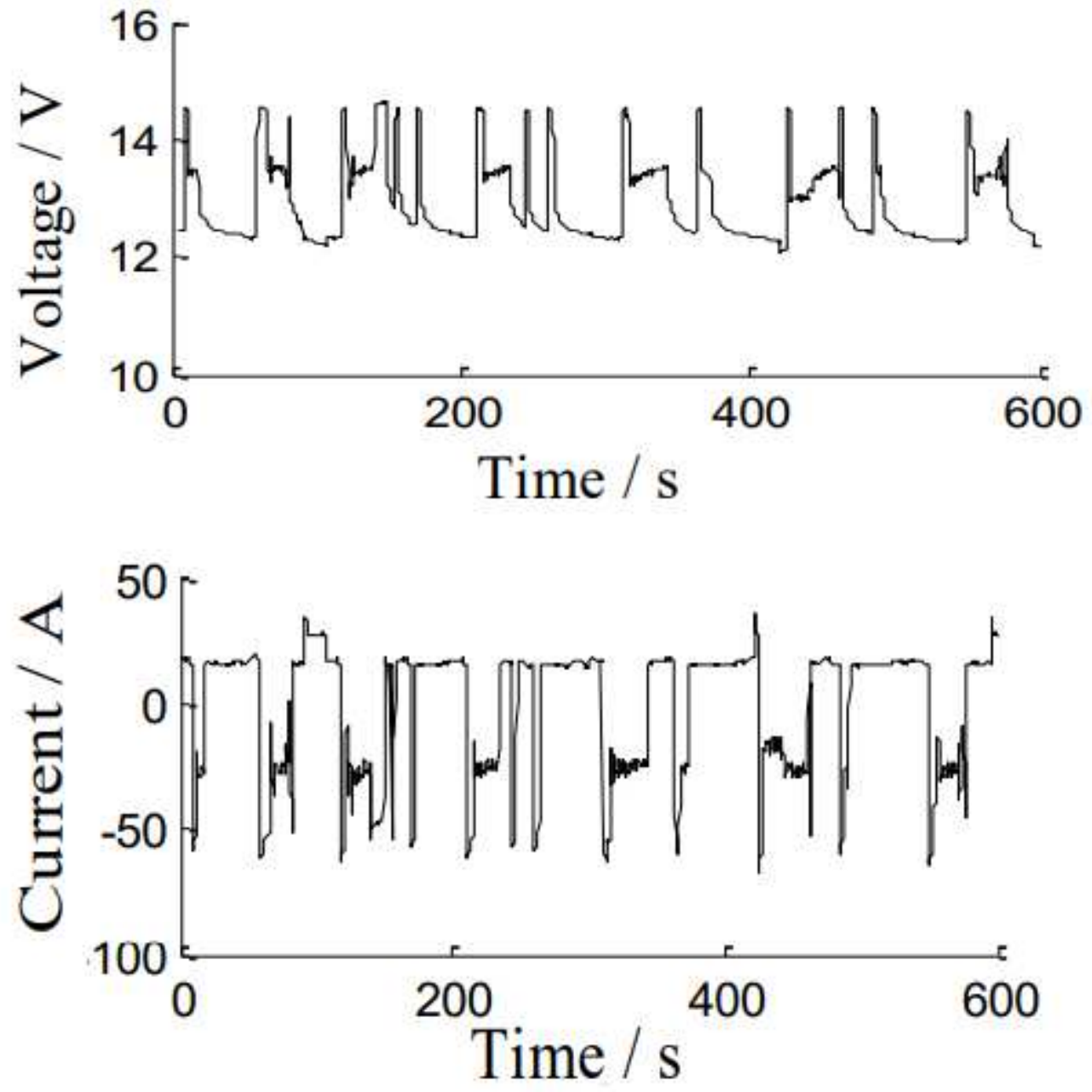

Figure 13

Battery voltage and current for vehicle with proposed management. 


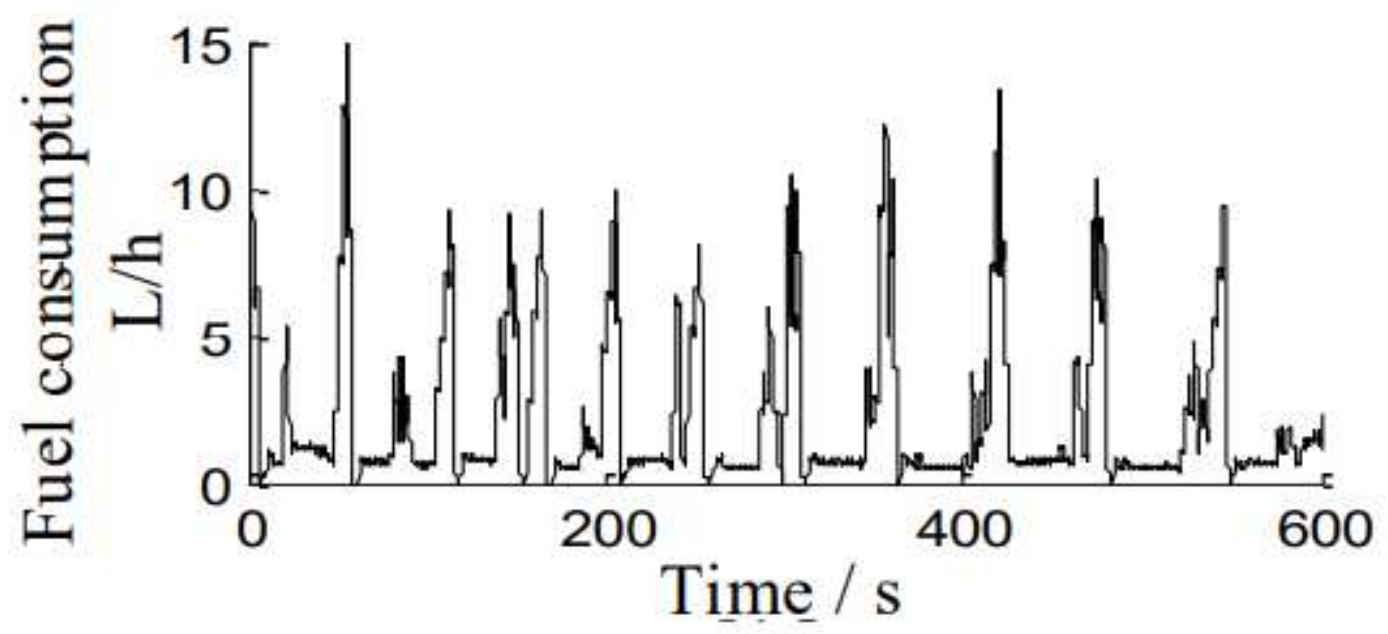

(a) vehicle with conventional management

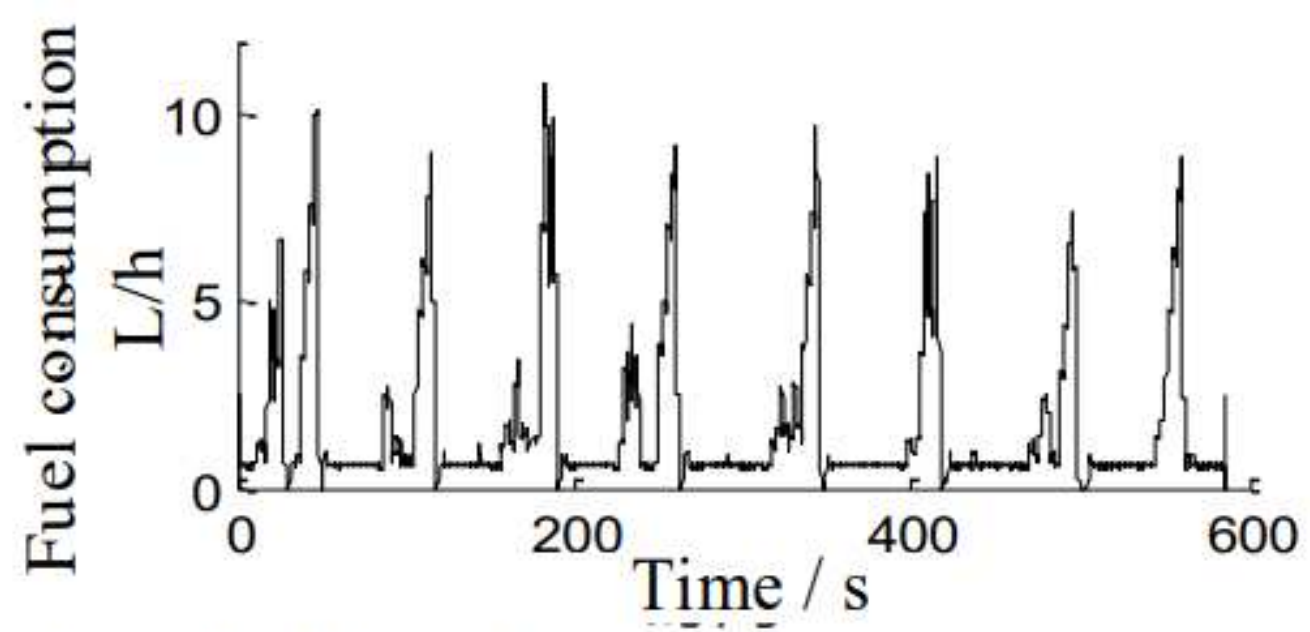

(b) vehicle with optimization system

Figure 14

Comparison of fuel consumption. 